NUMERICAL MODELLING OF CONTRACTED SHARP CRESTED WEIRS

A THESIS SUBMITTED TO

THE GRADUATE SCHOOL OF NATURAL AND APPLIED SCIENCES

$\mathrm{OF}$

MIDDLE EAST TECHNICAL UNIVERSITY

BY

AYSEL DURU

IN PARTIAL FULFILLMENT OF THE REQUIREMENTS

FOR

THE DEGREE OF MASTER OF SCIENCE

IN

CIVIL ENGINEERING

NOVEMBER 2014 

Approval of the thesis:

\section{NUMERICAL MODELLING OF CONTRACTED SHARP CRESTED WEIRS}

submitted by AYSEL DURU in partial fulfillment of the requirements for the degree of Master of Science in Civil Engineering Department, Middle East Technical University by,

Prof. Dr. M. Gülbin Dural Ünver

Director, Graduate School of Natural and Applied Sciences

Prof. Dr. Ahmet CevdetYalçıner

Head of Department, Civil Engineering

Prof. Dr. A. Burcu Altan-Sakarya

Supervisor, Civil Engineering Dept., METU

Assoc. Prof. Dr. M. Ali Kökpınar

Co-Supervisor, General Directorate of State Hydraulic Works

\section{Examining Committee Members:}

Prof. Dr. Mustafa Gögüus

Civil Engineering Dept., METU

Prof. Dr. A. Burcu Altan-Sakarya

Civil Engineering Dept., METU

Assoc. Prof. Dr. M. Ali Kökpınar

General Directorate of State Hydraulic Works

Assoc. Prof. Dr. Mete Köken

Civil Engineering Dept., METU

Özgün Güler, M.Sc.

İOG Engineering

Date: November, 27, 2014 
I hereby declare that all information in this document has been obtained and presented in accordance with academic rules and ethical conduct. I also declare that, as required by these rules and conduct, I have fully cited and referenced all the material and results that are not original to this work.

Name, Last name: Aysel, Duru

Signature 


\begin{abstract}

\author{
Duru, Aysel \\ M.S., Department of Civil Engineering \\ Supervisor: Prof. Dr. A. Burcu Altan-Sakarya \\ Co-Supervisor: Assoc. Prof. Dr. M. Ali Kökpınar
}

NUMERICAL MODELLING OF CONTRACTED SHARP CRESTED WEIRS

November 2014, 44 pages

Sharp crested weirs and gates are flow measurement structures which are frequently used for discharge measurements in channels and laboratories. In this thesis, numerical modelling technique was used in the solution of two flow measurement problems, namely contracted sharp crested weirs (Problem 1) and combined weir and gate system (Problem 2). The numerical simulation of flow cases having similar conditions with the experiments from the previous studies is performed for both Problem 1 and 2. The basic flow equations are solved using the finite-volume method of the commercially available software Flow-3D. The computed results for the volumetric flow rate of the flow are compared with the experimental data. The comparisons of the experimental and numerical results for both problems studied show that the computational volumetric flow rate values are found to agree reasonably well with the experimental data.

Keywords: Discharge measurement, numerical simulation, contracted sharp crested weirs, combined weir and gate system 


\title{
ÖZ
}

\section{DARALTILMIŞ İNCE KENARLI SAVAKLARIN SAYISAL MODELLEMESI}

\author{
Duru, Aysel \\ Yüksek Lisans, İnşaat Mühendisliği Bölümü \\ Tez Yöneticisi: Prof. Dr. A. Burcu Altan-Sakarya \\ Ortak TezYöneticisi: Doç. Dr. M. Ali Kökpınar
}

Kasim 2014, 44 sayfa

İnce kenarlı savaklar ve kapaklar, kanal ve laboratuvarlarda debi ölçümlerinde sıklıkla kullanılan akım ölçüm yapılarıdır. Bu tez çalışmasında; sayısal modelleme tekniği, ince kenarlı savaklar (Problem 1) ve savak ve kapakların kombine sistemi (Problem 2) olmak üzere iki akım ölçüm problemi için kullanıldı. Her iki problemde sayısal simülasyonlar önceki çalışmalardaki deneysel şartlarda gerçekleştirilmiştir. Akıma ait temel denklemler sonlu hacimler yöntemi kullanan Flow-3D yazılımı ile çözülmüştür. Hesaplanan akım debisi deneysel verilerle karşılaştırılmıştır. Her iki problem için de deneysel ve sayısal sonuçların karşıllaştırılması, hesaplanan debi değerlerinin deneysel veri ile makul ölçüde uyum sağladığını göstermiştir.

Anahtar Kelimeler: Debi ölçümü, sayısal modelleme, daraltılmış ince kenarlı savaklar, birleşik savak ve kapak sistemleri 


\section{ACKNOWLEDGEMENTS}

I would like to express my sincere gratitude to the following people for their tremendous help and support. Without their encouragement and guidance, I would never have been able to realize this work.

First and foremost, I would like to express my greatest appreciation to my thesis supervisor Prof. Dr. A. Burcu Altan-Sakarya for her patience, unlimited support, enthusiasm, and valuable comments. I would like to show gratitude to my cosupervisor Assoc. Prof. Dr. M. Ali Kökpınar for his guidance, comments and support. I feel motivated and encouraged whenever I talk to him.

I would like to express my sincere gratitude to the people who give a magic touch to my life, Ayfer Duru and Zeynel Eminoğlu. I am very grateful for their eternal friendship, moral support, and great contributions.

Last but not the least, I send heartfelt thanks to my mother, my sister, and my brother. They put faith in me all through my life and without their support and encouragement nothing would be possible. I am so glad that I have you. 


\section{TABLE OF CONTENTS}

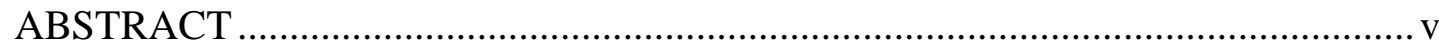

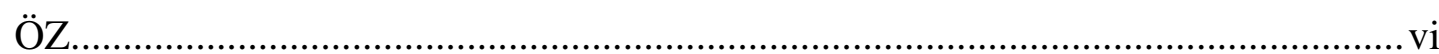

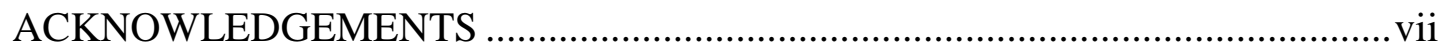

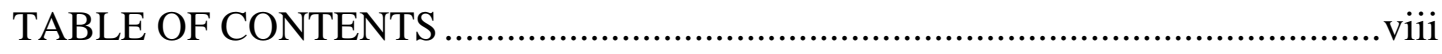

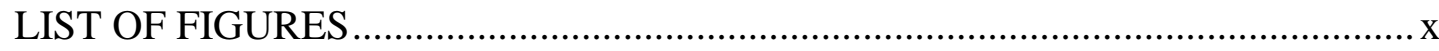

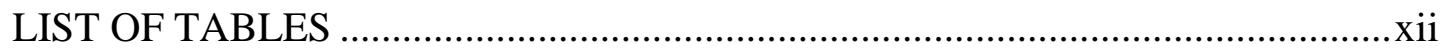

LIST OF ABBREVIATIONS .......................................................................

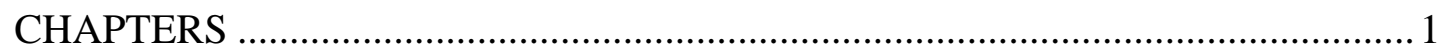

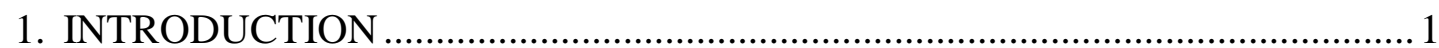

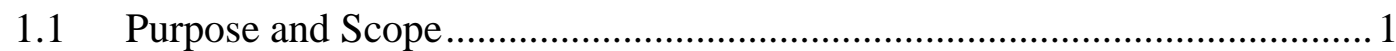

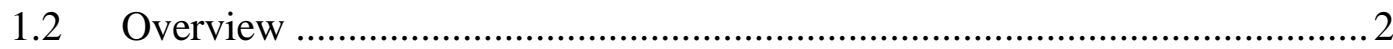

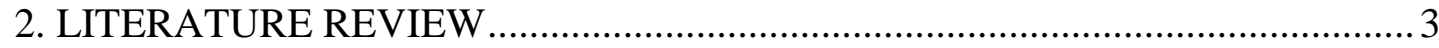

2.1 Contracted Sharp Crested Weir (Problem 1) …........................................... 3

2.2 Combined Weir and Gate System (Problem 2) ......................................... 6

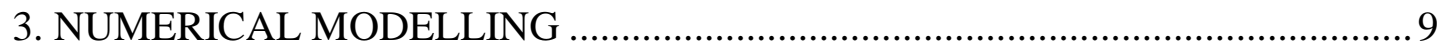

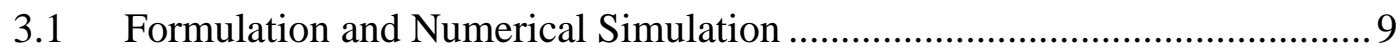

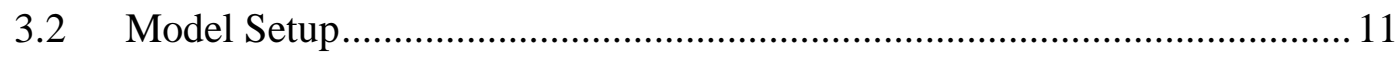

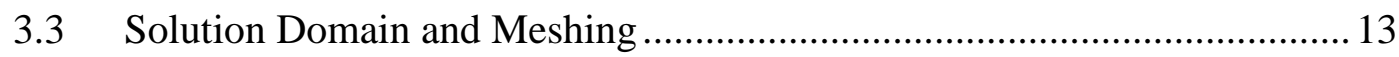

3.4 Initial and Boundary Conditions........................................................ 15

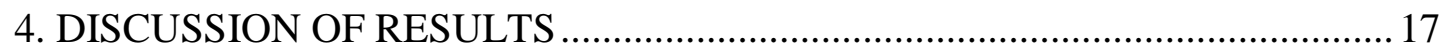




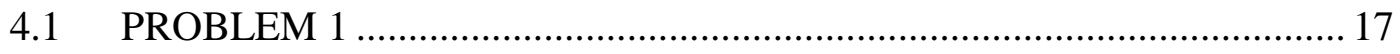

4.1.1 Effect of Mesh Size ....................................................................... 19

4.1.2 The Effect of Turbulence Model...................................................... 20

4.1.3 Effect of Upstream Channel Length ................................................. 21

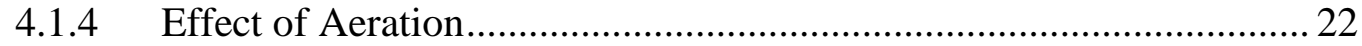

4.1.5 Numerical Simulations Using Various Upstream Flow Depths ......... 22

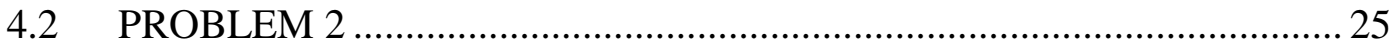

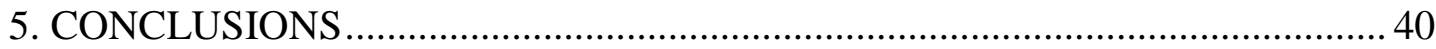

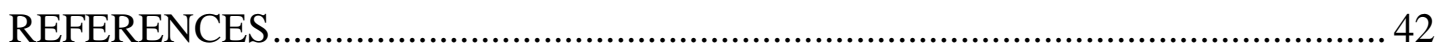




\section{LIST OF FIGURES}

\section{FIGURES}

Figure 2.1 A typical view of a contracted sharp crested weir (Aydin et al., 2011)...... 4

Figure 2.2 Side view of the contracted sharp crested weir (Aydın et al., 2011) ..........5

Figure 2.3 Geometrical definition of a combined weir and gate system (Problem 2)..7

Figure 2.4 Side view of a combined weir and gate system (Problem 2) .................... 7

Figure 3.1 Volume of Fluid Method Representation : a) 1-D View b) 2-D View ... 11

Figure 3.2 General 3D views of solid models constructed for a) Contracted sharp ...... crested weir (Problem 1) b) Combined weir and gate system (Problem 2). 12

Figure 3.3 View of the solution domains taken as symmetry of solid models for

a) Problem 1 and b) Problem 2 14

Figure 3.4 View of the boundary conditions on the solid model of a) Problem 1 and ..

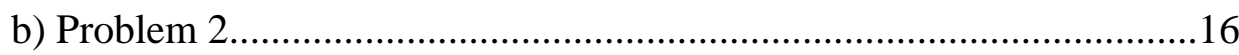

Figure 4.1 Coincidence of numerical and experimental results .............................2 24

Figure 4.2 Differences between experimental and numerical results ......................24

Figure 4.3 Velocity magnitude from the simulation result for RUN B2 (in m/s) .....26

Figure 4.4 Comparison of $Q_{C F D}$ with $Q_{c a l}$ for Combined Weir and Gate Systems-A....

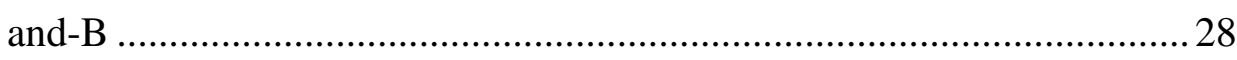

Figure 4.5 Velocity magnitude contours for RUN-A1 (in m/s) ...............................2 29

Figure 4.6 Velocity magnitude and vectors for RUN-A1(in m/s)..........................29

Figure 4.7 Velocity magnitude contours for RUN-A2 (in m/s) .............................. 30

Figure 4.8 Velocity magnitude and vectors for RUN-A2 (in $\mathrm{m} / \mathrm{s}$ )............................30

Figure 4.9 Velocity magnitude contours for RUN-A3 (in $\mathrm{m} / \mathrm{s}$ ) ................................ 31

Figure 4.10 Velocity magnitude and vectors for RUN-A3 (in $\mathrm{m} / \mathrm{s}$ )............................ 31

Figure 4.11 Velocity magnitude contours for RUN-A4 (in m/s) ................................. 32 
Figure 4.12 Velocity magnitude and vectors for RUN-A4 (in $\mathrm{m} / \mathrm{s}$ ) ......................... 32

Figure 4.13 Velocity magnitude contours for RUN-B1 (in m/s) ............................. 33

Figure 4.14 Velocity magnitude and vectors for RUN-B1 (in $\mathrm{m} / \mathrm{s}$ )......................... 33

Figure 4.15 Velocity magnitude contours for RUN-B2 (in m/s) ............................. 34

Figure 4.16 Velocity magnitude and vectors for RUN-B2 (in $\mathrm{m} / \mathrm{s}$ )......................... 34

Figure 4.17 Velocity magnitude contours for RUN-B3 (in m/s) .............................. 35

Figure 4.18 Velocity magnitude and vectors for RUN-B3 (in $\mathrm{m} / \mathrm{s}$ )......................... 35

Figure 4.19 Velocity magnitude contours for RUN-B4 (in m/s) ............................ 36

Figure 4.20 Velocity magnitude and vectors for RUN-B4 (in $\mathrm{m} / \mathrm{s}$ ) ......................... 36

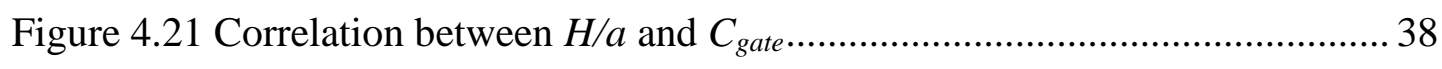

Figure 4.22 Correlation between $C_{d \text {,weir }}$ values and $h /(y+a)$ ratio............................ 39 


\section{LIST OF TABLES}

\section{TABLES}

Table 4.1 Summary of model test parameters affecting numerical simulation results for the first problem

Table 4.2 Experimental results of Aydın et al.(2011) used for the numerical

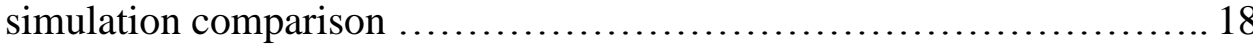

Table 4.3 Summary of the water levels used in the present study ..................19

Table 4.4 Mesh cell size effect on simulation results for $h=0.15 \mathrm{~m}$...............20

Table 4.5 Turbulence model effect for the data within the limit of experimental data range.

Table 4.6 Turbulence model effect for the data outside the limit of experimental

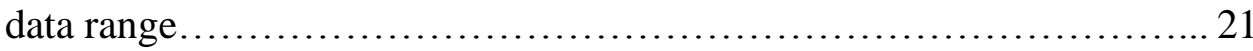

Table 4.7 Effect of upstream channel length on simulation results............... 22

Table 4.8 Comparison of the experimental and numerical results................. 23

Table 4.9 Comparison of $Q_{c a l}$ and $Q_{C F D}$ results for the combined weir and gate systems

Table 4.10 Discharge and discharge coefficients computed from CFD modelling

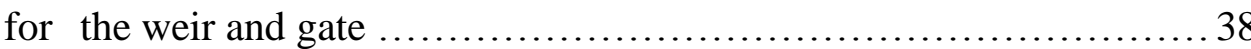




\section{LIST OF ABBREVIATIONS}

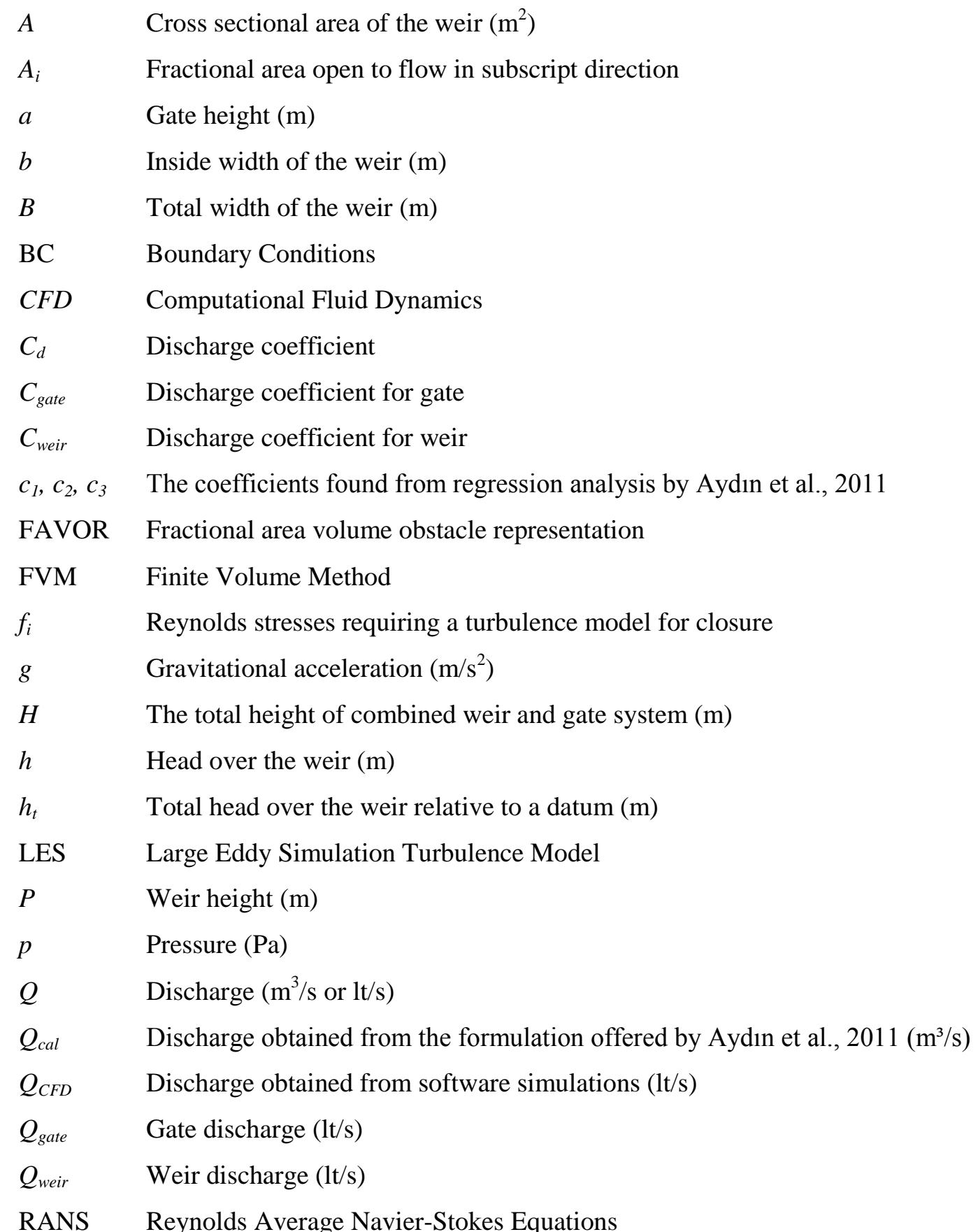


$R E \quad$ Relative Error

RNG Renormalized Group Turbulence Model

TruVOF Special model of VOF

$u_{i} \quad$ Velocity component in subscript direction $(\mathrm{m} / \mathrm{s})$

$u / s \quad$ Upstream

$V \quad$ Velocity of the weir $(\mathrm{m} / \mathrm{s})$

VOF Volume of Fluid

$V_{F} \quad$ Volume fraction of fluid in each cell

$V_{w c} \quad$ Average velocity at the weir section

$y \quad$ The opening between top of the gate and bottom of the weir (m)

$\Delta \mathrm{x}, \Delta \mathrm{y}, \Delta \mathrm{z} \quad$ Mesh sizes in $\mathrm{x}, \mathrm{y}, \mathrm{z}$ directions, respectively

$\rho \quad$ Fluid density $\left(\mathrm{kg} / \mathrm{m}^{3}\right)$ 


\section{CHAPTER 1}

\section{INTRODUCTION}

\subsection{Purpose and Scope}

Control sections are one of the most important devices in hydraulic engineering. The relationship between the discharge and the water level is fixed by channel control sections in open channels. Weirs are commonly used hydraulic structures as control devices to measure discharges. Sharp crested weirs are vertical obstructions placed normal to the flow direction. Water passes through a contracted section over the weir plate. Sharp crested weirs have some advantages that the flow is substantially free from viscous effects and resultant energy dissipation (Henderson, 1967; Aydın et al., 2011).

Analysis of flow over the weir is an important engineering problem. Therefore, recent developments in computer science and numerical techniques have advanced the use of Computational Fluid Dynamics (CFD) as a powerful tool for this purpose (Haun et al., 2011). Flow-3D is used as the numerical CFD simulation software which applies the finite volume method to solve Reynolds Average Navier-Stokes (RANS) Equations. To represent the sharp interface between air and water, for free surface flows, the Volume of Fluid (VOF) Method of Hirt and Nichols (1981) is used (Hargraves, 2007). This is a two phase approach where both water and air are modelled in the grid. The border between the geometry and the water is defined by the Fractional Area Volume Obstacle Representation (FAVOR) Method (Haun et al., 2011). Also, the continuity and momentum equations of the fluid fraction are formulated using FAVOR function (Kermani and Barani, 2014). 
In the scope of this thesis, two different problems were studied numerically. They are the contracted sharp crested weir as Problem 1 and the combined weir and gate system as Problem 2. For Problem 1, experimental results of the rectangular sharp crested weir were compared to the numerical results. For Problem 2, firstly, the system formed of gate and weir was solved as a combined system numerically. Then, the discharges of the weir and gate were obtained with the help of baffle option in the software and discharge coefficients were compared to experimental ones.

\subsection{Overview}

In Chapter 1, purpose and scope of the thesis are summarized.

The literature review of the two problems is given in Chapter 2. The geometrical definitions of the problems and related formulations are also available in Chapter 2.

In Chapter 3, numerical modelling is determined. Numerical simulation principles, software model setup for both problems, solution domain and meshing for the geometries, and initial and boundary conditions are explained in this chapter.

Results are discussed in Chapter 4. Determination of physical conditions to have an appropriate simulation model and effects of these properties such as mesh size, turbulence model, and upstream channel length are discussed in this chapter. In addition, the comparison and validation of the experimental and numerical results are analyzed in Chapter 4.

Conclusions are remarked in the last chapter. In Chapter 5, the suggestions to be helpful for later studies are specified. 


\section{CHAPTER 2}

\section{LITERATURE REVIEW}

Discharge measurement is an important issue in hydraulic engineering. Weir is one of the flow measuring devices for open channels. They are defined as structures where the streamlines parallel to each other over the weir and the crest of the weir is horizontal. Weirs are used as discharge measurement structures, for example in hydropower structures, irrigation channels and laboratory flumes (Haun et al., 2011). Contracted sharp crested weirs are also vertical obstructions placed normal to the flow direction in which water passes through a contracted section over the weir plate (Aydin et al., 2011).

Recent developments in computer science and numerical techniques have advanced the use of Computational Fluid Dynamics (CFD) as a powerful tool. CFD is a type of numerical method used to solve problems involving fluid flow. Since CFD can provide a faster and more economical solution than physical models, engineers are interested in verifying the capability of CFD software. Some recent works show the capability of the CFD method in the numerical modeling of flow over weirs (Kermani and Barani, 2014). In this study, Flow 3D is used as CFD software tool, which is capable of simulating the dynamic and steady state behaviors of the fluid (Afshar et al., 2013).

\subsection{Contracted Sharp Crested Weir (Problem 1)}

The weir is called sharp crested such that the head-discharge relationship will not be affected from the crest length of the weir. For this condition to occur, the flow depth above the weir crest should be greater than about 15 times the crest length. The crest 
length is normally less or equal to $2 \mathrm{~mm}$. Rectangular sharp crested weirs can be classified as partially contracted and full width weirs (Bos, 1989). In this study, a partially contracted weir is analyzed by using numerical simulation. Since the weir is contracted from the sides, $b / B$ ratio is reduced (Aydin et al., 2011).

For a rectangular weir, Equation (2.1) can be used as (Aydın et al., 2011)

$$
Q=\frac{2}{3} C_{d} \sqrt{2 g} b h^{3 / 2}
$$

where

$Q: \operatorname{discharge}\left(\mathrm{m}^{3} / \mathrm{s}\right)$

$b:$ weir width $(\mathrm{m})$

$h:$ head over the weir $(\mathrm{m})$

$g:$ gravitational acceleration $\left(\mathrm{m} / \mathrm{s}^{2}\right)$

$C_{d}$ : discharge coefficient (to represent all effects that are not taken into consideration such as viscous effect or streamline curvature)

A typical view of a contracted sharp crested weir and its side view are given in Figures 2.1 and 2.2, respectively.

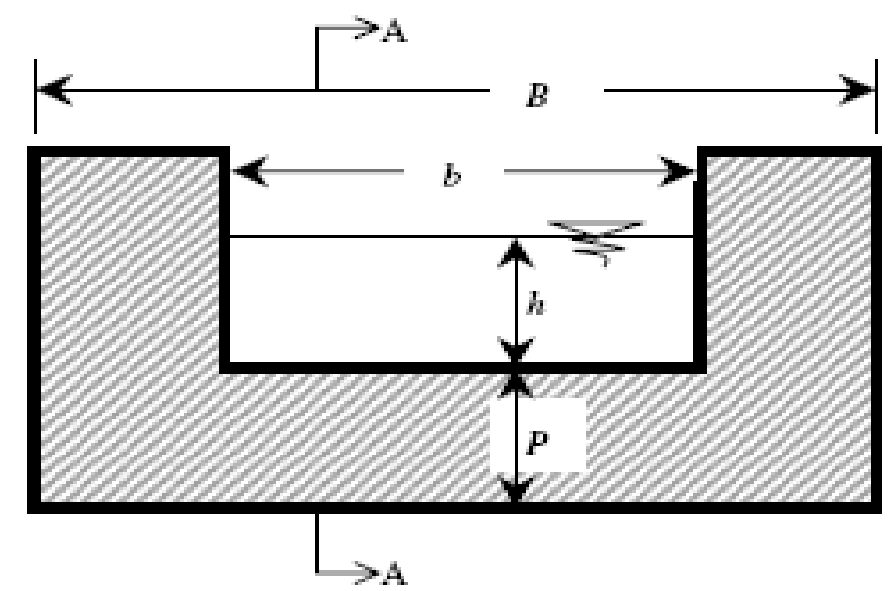

Figure 2.1 A typical view of a contracted sharp crested weir (Aydın et al., 2011) 
where

$B$ is the channel width (m)

$b$ is the weir opening $(\mathrm{m})$

$P$ is the weir height $(\mathrm{m})$

$h$ is the water level above the weir crest (m)

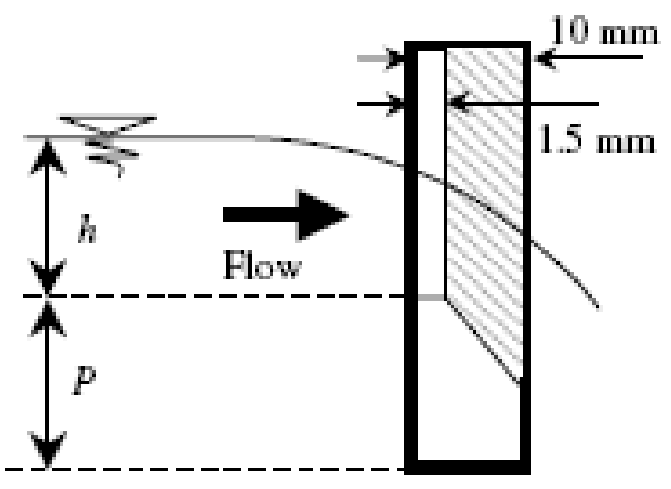

Figure 2.2 Side view of the contracted sharp crested weir (Aydın et al., 2011)

Experimental data for the contracted weir (Problem 1) obtained from the studies of Şisman (2009) and Aydın et al.(2011) were used in the verification of numerical simulations. For the present study, effects of the different parameters (mesh size, turbulence model, upstream channel length) and formulation validation for the outside of the experimental range for this experiment were estimated with the help of the numerical simulations. For the discharge coefficient, $C_{d}$, calculations; Rehbock (1929); Kindsvater and Carter (1957); Swamee (1988); Ramamurthy et al. (1987); Bagheri and Heidarpour (2010a and 2010b) suggested different formulations in literature. The results taken from the numerical simulations were compared with the results of the formulation suggested by Aydin et al. (2011). They suggested the following equations for the calculation of discharge as,

$$
Q=V_{w c} A
$$

where $A$ is cross sectional area of the flow $\left(\mathrm{m}^{2}\right)$ and $V_{w c}$ is the average velocity at the weir section $(\mathrm{m} / \mathrm{s})$ which is calculated by Equation (2.3). 


$$
V_{w c}=c_{1}+c_{2} h+c_{3} h^{1.5}
$$

where $c_{1}, c_{2}$ and $c_{3}$ are the coefficients found from regression analysis given as,

$$
\begin{aligned}
& c_{1}=0.252-0.068(b / B)+0.002(b / B)^{2} \\
& c_{2}=3.937+0.760(b / B)+2.426(b / B)^{2} \\
& c_{3}=-2.238-2.856(b / B)-1.427(b / B)^{2}
\end{aligned}
$$

The given formulation is valid for $\mathrm{b} / \mathrm{B}>0.25$ and up to $\mathrm{a} \mathrm{h}_{\max }$, head over the weir, of $0.2796 \mathrm{~m}$.

\subsection{Combined Weir and Gate System (Problem 2)}

Weirs and gates are commonly used to measure discharge in open channels. These are obstructions generally put normal to the direction of the flow. The combined weir and gate structure shown in Figure 2.3 and Figure 2.4 is a relatively new system suggested by several researches, compared to extensive use of weirs and gates individually (Alhamid, 1999; Ferro, 2000; Negm et al., 2002; Altan-Sakarya et al., 2005; Askeroğlu, 2006; Altan-Sakarya and Kökpınar, 2013). In the present study of the combined system, the gate is rectangular while the weir part is trapezoidal, as studied by Askeroğlu, (2006). 


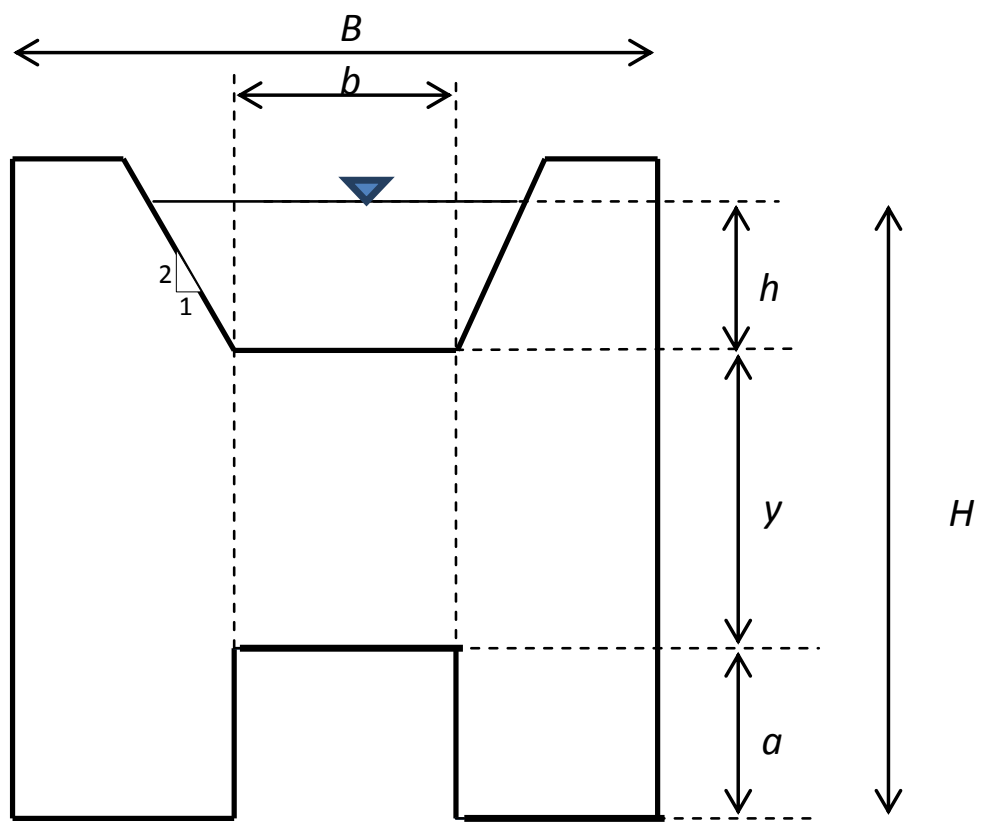

Figure 2.3 Geometrical definitions of a combined weir and gate system (Problem 2)

where

$a$ is the gate height (m).

$y$ is the opening between top of the gate and bottom of the weir (m).

$h$ is the weir height (m).

$H$ is the total height (m).

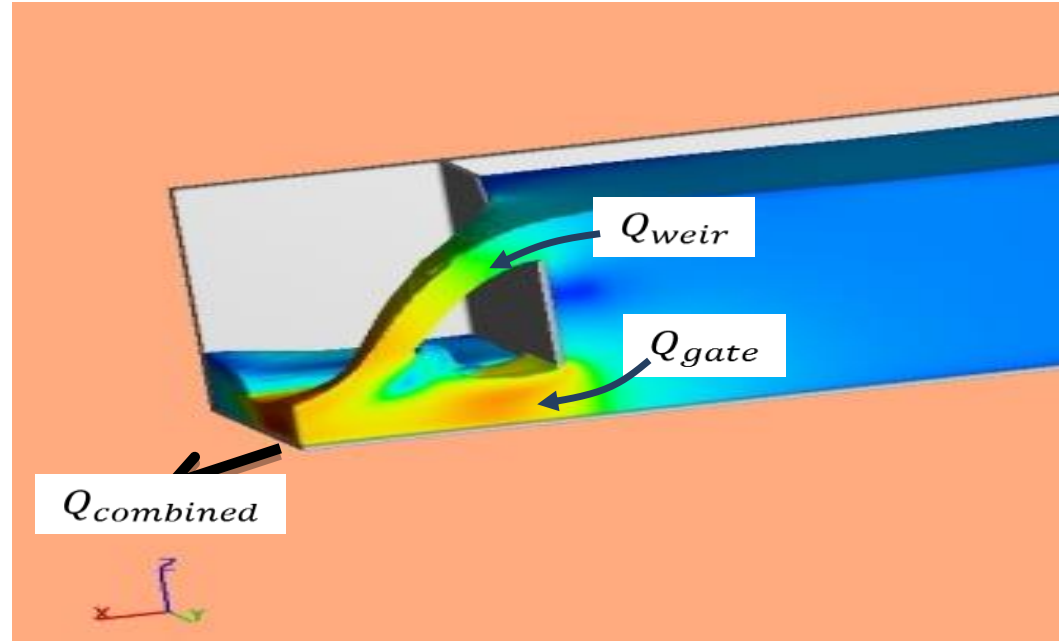

Figure 2.4 Side view of a combined weir and gate system (Problem 2) 
For a combined weir and gate system, the combined discharge, $Q_{\text {combined }}$, is obtained by the sum of weir and gate discharges as given below,

$$
Q_{\text {combined }}=Q_{\text {weir }}+Q_{\text {gate }}
$$

where $Q_{\text {weir }}$ is the discharge passing through the weir and $Q_{\text {gate }}$ is the discharge passing through the gate.

For an individual trapezoidal weir, Askeroğlu (2006) computed the discharge from

$$
Q_{\text {weir }}=\frac{2}{3} C_{\text {weir }} \sqrt{2 g} h^{\frac{3}{2}}\left(b+\frac{2}{5} h\right)
$$

where $C_{w e i r}$ is the discharge coefficient for the trapezoidal weir.

Similarly, for an individual rectangular gate, Askeroğlu (2006) computed the discharge from

$$
Q_{\text {gate }}=C_{\text {gate }} a b \sqrt{2 g H}
$$

where $C_{\text {gate }}$ is the discharge coefficient for the gate.

In all experimental studies given in literature, measurements of weir and gate discharges could not be separated due to experimental difficulties and all discharge analyses were based on the measured combined discharge values. Within the scope of this thesis, $C_{\text {weir }}$ and $C_{\text {gate }}$ coefficients will be estimated independently with the use of CFD simulation techniques and the comparison of combined weir and gate system to individual operation of weir and gate will be made. 


\section{CHAPTER 3}

\section{NUMERICAL MODELLING}

\subsection{Formulation and Numerical Simulation}

Fluid motion is described with non-linear, transient, second-order differential equations. The fluid equations of motion must be employed to solve these equations. The science of developing these methods is called computational fluid dynamics. Computational Fluid Dynamics (CFD) modelling employs specially developed numerical techniques to solve the equations of motion for fluids to obtain transient, three-dimensional solutions to multi-scale, multi-physics flow problems. A numerical solution of these equations involves approximating the various terms with algebraic expressions. The resulting equations are then solved to yield an approximate solution to the original problem. The process is called simulation. The average values of flow parameters such as pressure and velocity are determined for each cell, with the help of gridding system. The representation of the boundary condition is also an important step for accurate simulation.

For three dimensional (3D) free surface flow simulations, the numerical solutions of RANS (Reynold Average Navier- Stokes) equations are solved by using Flow-3D software based on FVM (Finite Volume Method) in a Cartesian, staggered grid (Hirt and Nichols, 1981). Flow-3D is commercially available CFD software, capable of solving a wide range of fluid flow problems.

The governing continuity and RANS equations for Newtonian, incompressible fluid flow are (Ozmen-Cagatay and Kocaman, 2010):

$$
\frac{\partial}{\partial x_{i}}\left(u_{i} A_{i}\right)=0
$$




$$
\frac{\partial u_{i}}{\partial t}+\frac{1}{V_{F}}\left(u_{j} A_{j} \frac{\partial u_{i}}{\partial x_{j}}\right)=-\frac{1}{\rho} \frac{\partial p}{\partial x_{i}}+g_{i}+f_{i}
$$

where $u_{i}$ represents velocity component in subscript direction, $V_{F}$ is volume fraction of fluid in each cell, $A_{i}$ is fractional area open to flow in subscript direction, $p$ is pressure, $\rho$ is fluid density, $t$ is time, $g_{i}$ is gravitational force in subscript direction, $f_{i}$ is Reynolds stresses requiring a turbulence model for closure, $V_{F}$ and $A_{i}$ (cell face areas) $=1$, thereby reducing the equations to the basic incompressible RANS equations.

The Volume of Fluid (VOF) method is employed in Flow-3D. It consists of three main components: the definition of the volume of fluid function, a method to solve the VOF transport equation and setting the boundary conditions at the free surface.

Flow-3D utilizes TruVOF method for computing free surface motion, and complex geometric regions are modeled using the area/volume obstacle representation (FAVOR) method. In the TruVOF method, a special advection technique is used that gives a sharp definition of the free surface and does not compute the dynamics in the void or air regions. The portion of volume or area occupied by the obstacle in each cell is defined at the beginning of the analysis, and the fluid fraction in each cell is also calculated. The continuity and momentum equations of the fluid fraction are formulated using the FAVOR function, and the finite volume method or a finite difference approximation is used for the discretization and solving of each equation (Flow Inc., User Manual v10). The FAVOR Method is represented on Figure 3.1 as below. 
a)

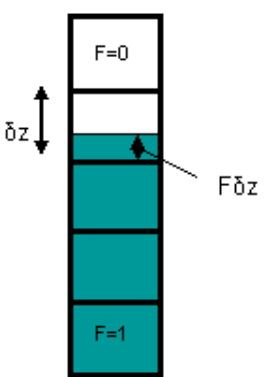

b)

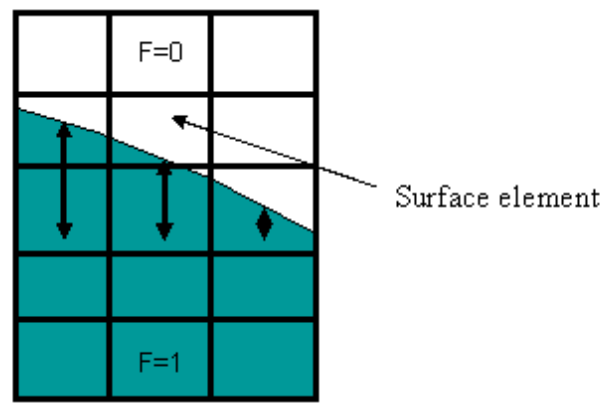

Figure 3.1 Volume of Fluid Method Representation : a) 1-D View b) 2-D View (http://www.flow3d.com/home/resources/cfd-101/free-surface-fluid-flow)

Turbulence is an important parameter hence it cannot be ignored in the simulations. Flow-3D can simulate the turbulence process by using mass and momentum conservation equations. In Flow-3D, there are five turbulence models available. These are the Prandtl mixing length model, the one-equation, the two-equation k- $\varepsilon$ and Renormalized Group (RNG) models, and a large eddy simulation (LES model) (Flow Inc., User Manual v10).

The RNG approach applies statistical methods to the derivation of the averaged equations for turbulence quantities, such as turbulent kinetic energy and its dissipation rate. It uses equations similar to the equations for the $\mathrm{k}-\varepsilon$ model. However, equation constants that are found empirically in the standard k- $\varepsilon$ model are derived explicitly in the RNG model. Generally, the RNG model has wider applicability than the standard k- $\varepsilon$ model. RNG is commonly used for the simulations of weir problems (Flow Inc., User Manual v10).

\subsection{Model Setup}

The simulations described in this thesis are run using version 10.0 of Flow-3D software on a PC. The geometries of both weir structures are created by using Flow3D's solid modeler. One solid component with 6 subcomponents for Problem 1 and one solid component with eight subcomponents for Problem 2 were created using simple box toolbar in the software (Figure 3.2). 


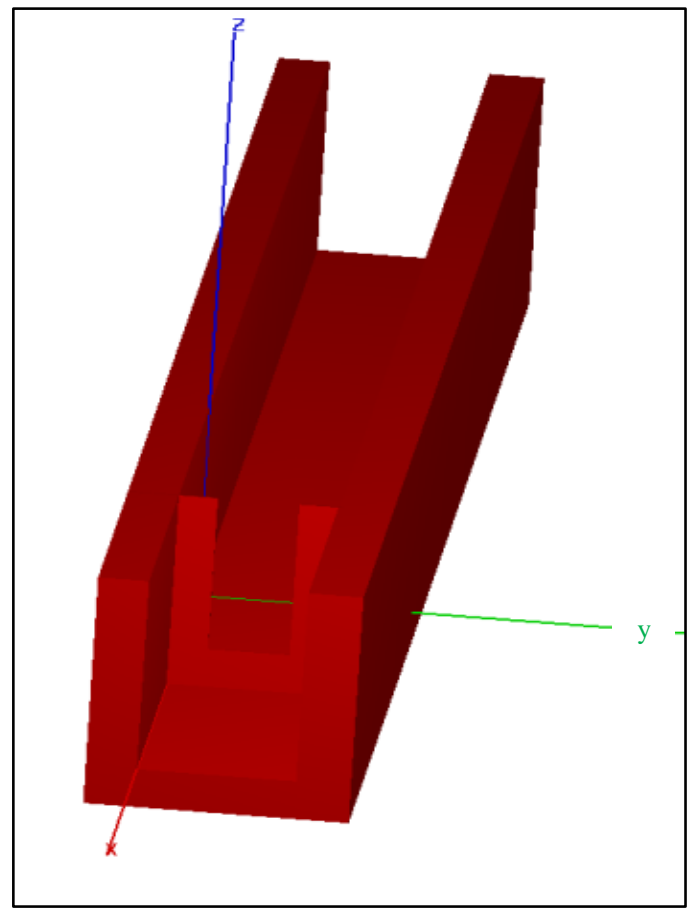

a)

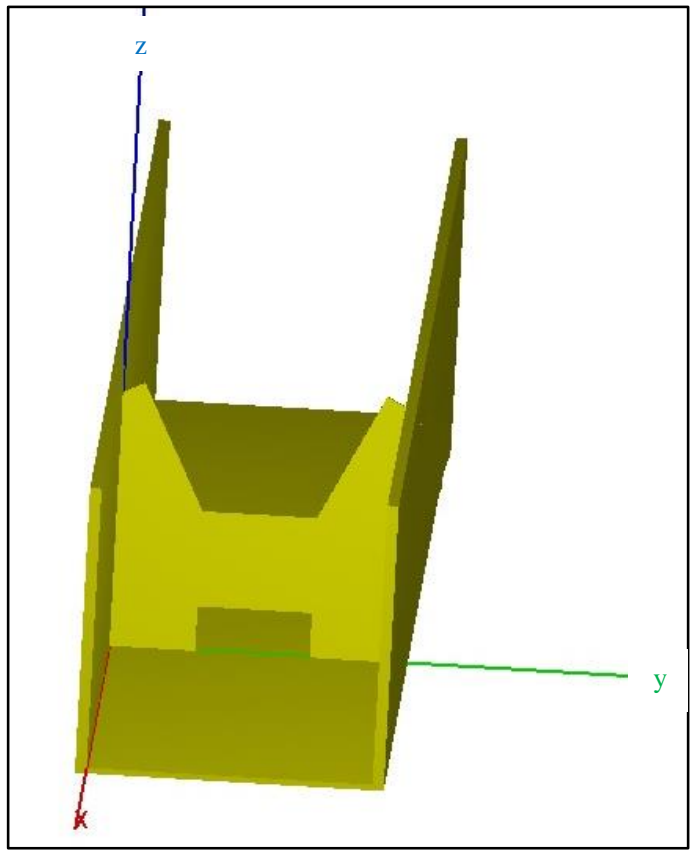

b)

Figure 3.2 General 3D views of solid models constructed for a) Contracted sharp crested weir (Problem 1) b) Combined weir and gate system (Problem2) 
For turbulence-viscosity options, RNG (for all simulation cases) was selected for both problems. In addition, LES was selected in only one simulation case for the turbulence model comparison. The gravitational force was taken along the (-) zdirection and after defining the fluid type from the "Materials" tool, water was chosen as the fluid type with its properties predefined within the software.

\subsection{Solution Domain and Meshing}

A computational mesh effectively discretizes the physical space. Each fluid parameter is represented in a mesh by an array of values at discrete points. Since the actual physical parameters vary continuously in space, a mesh with a fine spacing between nodes provides a better representation than a coarser one.

Meshing is an important step to solve the hydraulic systems in numerical modelling. Size of cells or total cell numbers is the options to define the mesh block in the Flow3D software. For the scope of this study, a constant cell size is specified to the model in meshing system instead of the number of total cells. Uniform mesh sizes of $\Delta \mathrm{x}=\Delta \mathrm{y}=\Delta \mathrm{z}=4 \mathrm{~mm}$ for the Problem 1 and $\Delta \mathrm{x}=\Delta \mathrm{y}=\Delta \mathrm{z}=5 \mathrm{~mm}$ for Problem 2 were used for the prescribed solution domain. Additionally, the effect of mesh size on simulation results and computation time were investigated by applying different mesh sizes. For this purpose, one uniform mesh block for Problem 1 is defined with cell sizes of $10 \mathrm{~mm}$ and $6 \mathrm{~mm}$, other than $4 \mathrm{~mm}$. Hence, the effect of mesh size on the results can be analyzed. To define a solution domain, created mesh block was taken half of the whole body in y-direction so that solution time optimized with the help of symmetry as shown in Figure 3.3(a) and Figure 3.3(b) for Problems 1 and 2, respectively. It should be noted that a baffle surface of Problem 2 was also appearing in the trapezoidal weir part of the solid model in Figure 3.3 (b). 


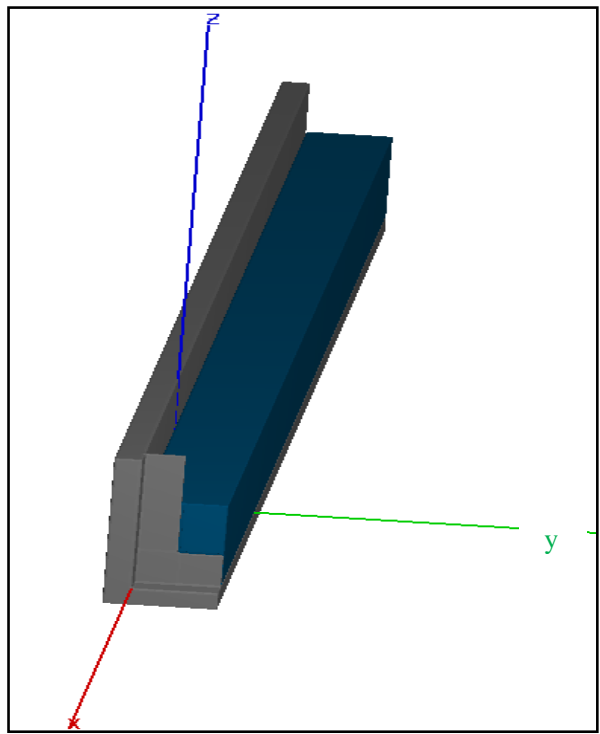

a)

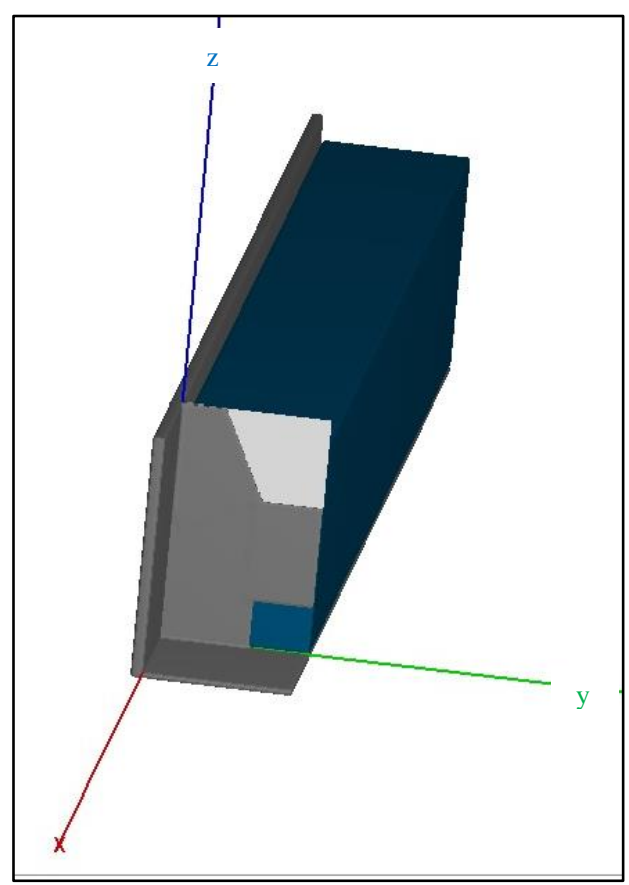

b)

Figure 3.3 View of the solution domains taken as symmetry of solid models for Problem 1, and b) Problem 2 


\subsection{Initial and Boundary Conditions}

Appropriate boundary conditions are to be set in the simulations to have a realistic result. The software includes six different boundaries since the flow domain is defined as a hexahedral Cartesian coordinates (Kermani and Barani, 2014).

Given in Figure 3.4 (a), initial and boundary conditions for Problem 1 can be summarized as follows,

- $\mathrm{X}$-min is chosen as pressure $(\mathrm{P})$ where water level is the input.

- X-max is outflow $(\mathrm{O})$

- $\quad$ Y-min and Z-min are wall (W)

- Y-max and Z-max are symmetry (S)

Similarly, in Figure 3.4 (b), boundary conditions for Problem 2 defined as

- $\mathrm{X}$-min is chosen as pressure $(\mathrm{P})$ where water level is the input.

- $\mathrm{X}$-max is outflow $(\mathrm{O})$

- Y-min and Z-min are wall (W)

- Y-max and Z-max are symmetry (S) 

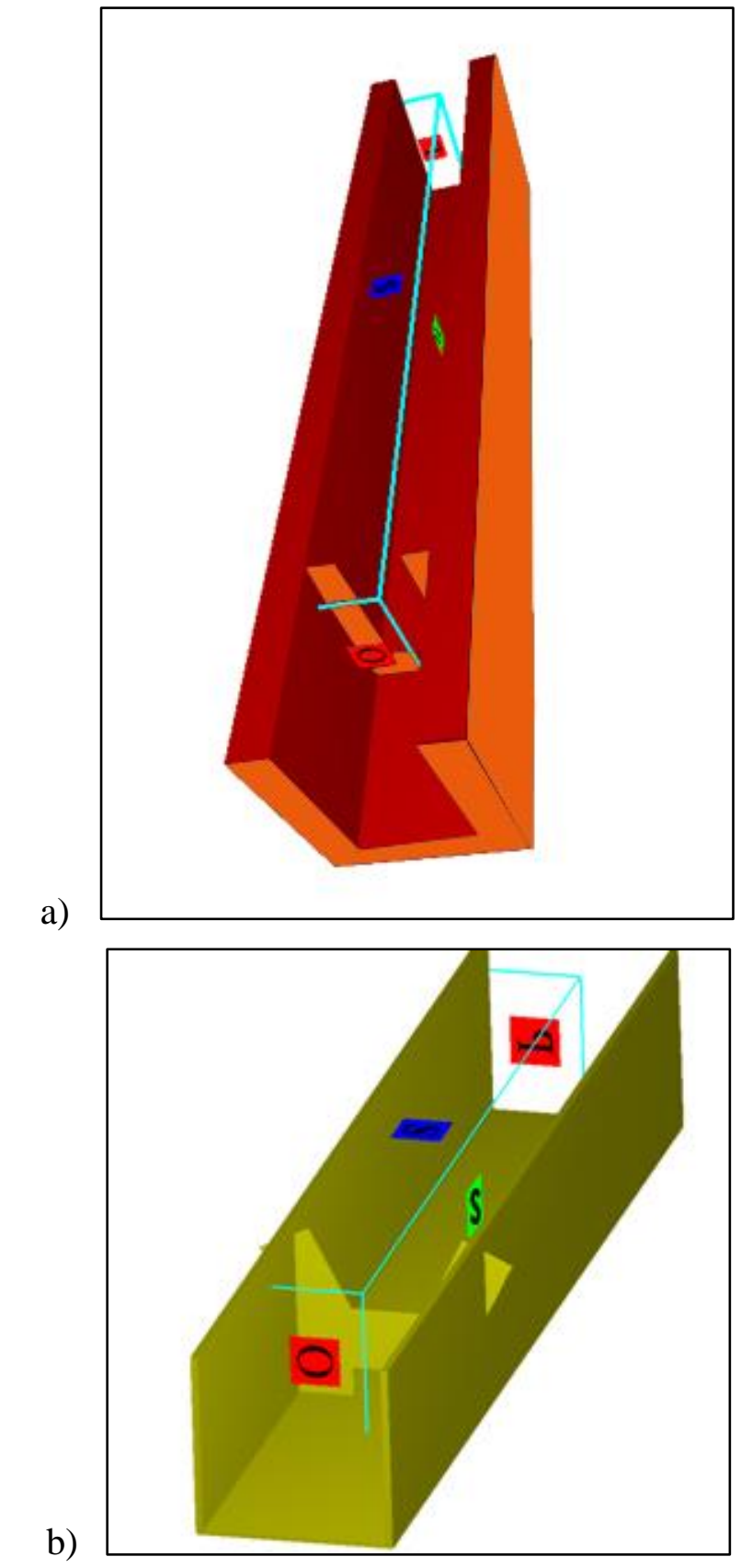

Figure 3.4 View of the boundary conditions on the solid model of a) Problem 1 and b) Problem 2 


\section{CHAPTER 4}

\section{DISCUSSION OF RESULTS}

\subsection{PROBLEM 1}

In Problem 1, the contracted sharp crested weir geometry studied by Aydin et al. (2011) was used as previously mentioned in Chapter 2. To obtain the optimum simulation model conditions for this geometry, the effects of

- mesh cell size

- turbulence model

- $\operatorname{upstream}(\mathrm{u} / \mathrm{s})$ channel length

were studied separately on a particular case with a defined upstream water depth. Then, after deciding the optimum model parameters with the specified physical definitions, the model was solved for the other water levels. The summary of the simulations for the first problem is given in Table 4.1.

Table 4.1 Summary of model test parameters affecting numerical simulation results for the first problem

\begin{tabular}{|l|c|l|}
\hline $\begin{array}{c}\text { Model parameter } \\
\text { tested }\end{array}$ & $\begin{array}{c}\text { Number of } \\
\text { Runs }\end{array}$ & \multicolumn{1}{|c|}{ Notes } \\
\hline mesh size & 3 & 4,6 and $10 \mathrm{~mm}$ uniform mesh sizes are tested \\
\hline turbulence model & 4 & $\begin{array}{l}\text { RNG and LES turbulence models are used within } \\
\text { and outside the experimental data ranges }\end{array}$ \\
\hline $\begin{array}{l}\text { upstream channel } \\
\text { length }\end{array}$ & 3 & $1,1.5$, and $2.5 \mathrm{~m}$ channel lengths are tested \\
\hline
\end{tabular}


In order to determine the accuracy of the simulation results, the Relative Error $(R E)$ of the experimental and the numerical discharge results are calculated using the equation given below

$$
R E=\frac{Q_{c a l}-Q_{C F D}}{Q_{c a l}} \times 100
$$

in which $Q_{c a l}$ is the experimentally measured discharge value and $Q_{C F D}$ is the discharge value obtained from simulation result.

For this study, only one $b / B$ ratio is studied as shown in Table 4.2 . For $b / B=0.5$; the experimental data range of the water level above the weir crest is between $h_{\min }=0.0256 \mathrm{~m}$ and $h_{\max }=0.2730 \mathrm{~m}$. In this numerical study, the studied range includes five data points within the experimental range of Aydın et al. (2011) and three data points outside the range for $h$. The values are given in Table 4.3. $h_{t}$ is the total depth of flow.

Table 4.2 Experimental results of Aydın et al.(2011) used for the numerical simulation comparison

\begin{tabular}{|c|c|c|c|c|c|c|c|}
\hline $\begin{array}{c}b \\
(\mathrm{~m})\end{array}$ & $b / B$ & $\begin{array}{c}Q_{\min } \\
\left(\mathrm{m}^{3} / \mathrm{s}\right)\end{array}$ & $\begin{array}{c}Q_{\max } \\
\left(\mathrm{m}^{3} / \mathrm{s}\right)\end{array}$ & $\begin{array}{c}h_{\min } \\
(\mathrm{m})\end{array}$ & $\begin{array}{c}h_{\max } \\
(\mathrm{m})\end{array}$ & $h_{\min } / b$ & $h_{\max } / b$ \\
\hline 0.16 & 0.50 & 0.00134 & 0.04348 & 0.0256 & 0.2730 & 0.16 & 1.71 \\
\hline
\end{tabular}


Table 4.3 Summary of the water levels used in the present study

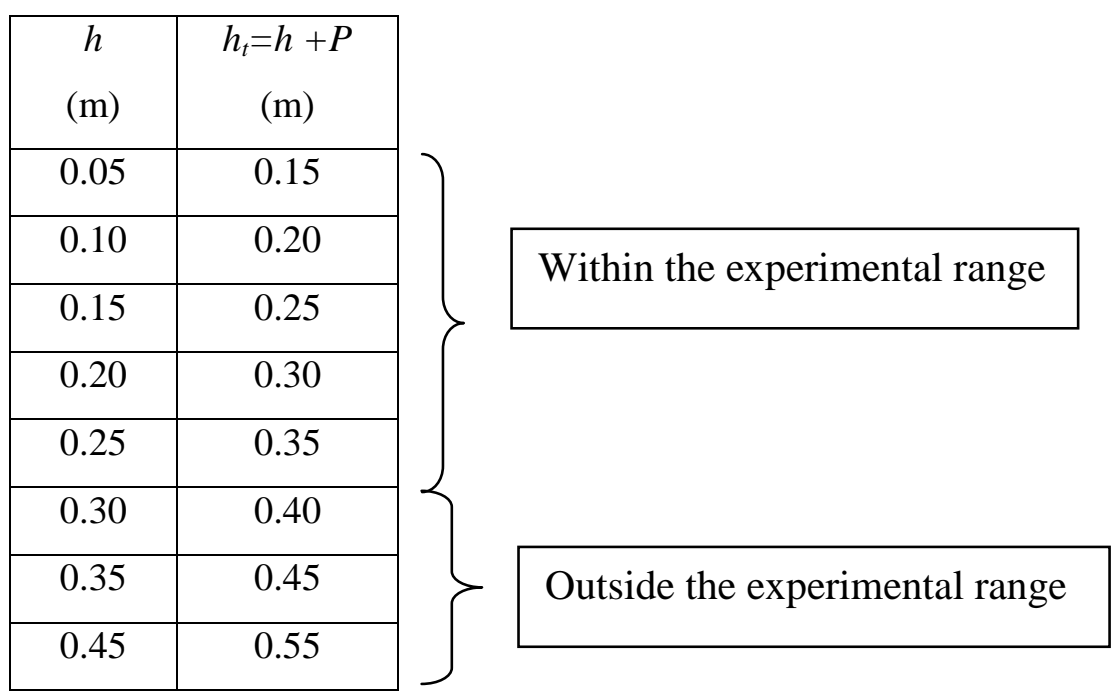

The results of the numerical study are compared to that of the empirical formulations given by Aydın et al. (2011) which are given in Chapter 2 between Equations (2.2) and (2.6).

\subsubsection{Effect of Mesh Size}

Determining the appropriate mesh size is an important part of the numerical simulation. Grid size can affect not only the accuracy of the result, but also simulation time. The mesh with fine spacing provides better representation to the reality than the coarser one. However, refining the mesh means more computational time and it increases the size of numerical model. In other words, when the mesh size becomes smaller, the total mesh number increases, but increasing mesh number gives better results. Consequently, it is important to minimize the number of grids while including enough and sufficient resolution flow details (Kermani and Barani, 2014; Flow Inc, User Manual, v10).

In this part of the study, different mesh sizes with 10,6 , and $4 \mathrm{~mm}$ are used to compare mesh size effect on $R E$ of the results and simulation time. For this comparison, simulations were performed at the same water depth, which is $h=0.15$ 
$\mathrm{m}$. As an input, cell size option is used to define the mesh system instead of defining total number of cells. After determining the mesh effect, the decision of the appropriate mesh size is made.

As expected, mesh size of $10 \mathrm{~mm}$ has the least simulation time and mesh size of 4 $\mathrm{mm}$ has the longest simulation time. However, the simulation with mesh size of 4 $\mathrm{mm}$ gives the best results with the lowest $R E$ value. Eventually, $4 \mathrm{~mm}$ for the mesh size is chosen for the other simulations. The results of these simulations are represented in Table 4.4 .

Table 4.4 Mesh cell size effect on simulation results for $h=0.15 \mathrm{~m}$

\begin{tabular}{|c|c|c|c|c|c|}
\hline $\begin{array}{c}\text { Mesh cell } \\
\text { size } \\
(\mathrm{mm})\end{array}$ & $\begin{array}{c}h_{t}=h+P \\
(\mathrm{~m})\end{array}$ & $\begin{array}{c}Q_{\text {cal }} \\
\left(\mathrm{m}^{3} / \mathrm{s}\right)\end{array}$ & $\begin{array}{c}Q_{C F D} \\
\left(\mathrm{~m}^{3} / \mathrm{s}\right)\end{array}$ & $\begin{array}{c}R E \\
(\%)\end{array}$ & $\begin{array}{c}\text { Simulation Time } \\
(\mathrm{hrs})\end{array}$ \\
\hline 10 & 0.25 & 0.01741 & 0.01956 & -12.35 & 0.26 \\
\hline 6 & 0.25 & 0.01741 & 0.01808 & -3.85 & 2.33 \\
\hline 4 & 0.25 & 0.01741 & 0.01740 & 0.06 & 32.00 \\
\hline
\end{tabular}

\subsubsection{The Effect of Turbulence Model}

In this part of the study, LES and RNG turbulence models are used in the numerical simulations. Totally, four simulations are performed to find the effect of the turbulence model on simulation results. The two of them are of RNG model and the other two are of LES model. The reason of applying two simulations for each one instead of single simulation for both cases is related to the experimental range. For each turbulence model, one simulation is done within the limit of experimental range conducted and the other is done for the outside of the experimental range. The results of the two different turbulence models are given in Table 4.5 and 4.6, respectively. 
Table 4.5 Turbulence model effect for the data within the experimental range

\begin{tabular}{|c|c|c|c|c|c|c|}
\hline $\begin{array}{c}\text { Turbulence } \\
\text { Model }\end{array}$ & $\begin{array}{c}h \\
(\mathrm{~m})\end{array}$ & $\begin{array}{c}h_{t}=h+P \\
(\mathrm{~m})\end{array}$ & $\begin{array}{c}Q_{\text {cal }} \\
\left(\mathrm{m}^{3} / \mathrm{s}\right)\end{array}$ & $\begin{array}{c}Q_{C F D} \\
\left(\mathrm{~m}^{3} / \mathrm{s}\right)\end{array}$ & $\begin{array}{c}R E \\
(\%)\end{array}$ & $\begin{array}{c}\text { Simulation } \\
\text { Time } \\
(\mathrm{hrs})\end{array}$ \\
\hline RNG & 0.15 & 0.25 & 0.01741 & 0.01740 & 0.057 & 32.11 \\
\hline LES & 0.15 & 0.25 & 0.01741 & 0.01740 & 0.057 & 32.11 \\
\hline
\end{tabular}

Table 4.6 Turbulence model effect for the data outside the experimental range

\begin{tabular}{|c|c|c|c|c|c|c|}
\hline $\begin{array}{c}\text { Turbulence } \\
\text { Model }\end{array}$ & $\begin{array}{c}h \\
(\mathrm{~m})\end{array}$ & $\begin{array}{c}h_{t}=h+P \\
(\mathrm{~m})\end{array}$ & $\begin{array}{c}Q_{\text {cal }} \\
\left(\mathrm{m}^{3} / \mathrm{s}\right)\end{array}$ & $\begin{array}{c}Q_{C F D} \\
\left(\mathrm{~m}^{3} / \mathrm{s}\right)\end{array}$ & $\begin{array}{c}R E \\
(\%)\end{array}$ & $\begin{array}{c}\text { Simulation } \\
\text { Time } \\
(\mathrm{hrs})\end{array}$ \\
\hline RNG & 0.30 & 0.40 & 0.04977 & 0.04988 & -0.221 & 54.44 \\
\hline LES & 0.30 & 0.40 & 0.04977 & 0.05022 & -0.904 & 53.72 \\
\hline
\end{tabular}

Although a slightly better $R E$ value was obtained from RNG turbulence model in Table 4.6, one can state that two turbulence models give almost the same results. However, the RNG model is preferred as the turbulence model for other simulation cases. It was also known from Hargreaves et al. (2007) that RNG model has known advantages when there is strong curvature in the streamlines as in the case with accelerating flow over a weir.

\subsubsection{Effect of Upstream Channel Length}

In this part of the study, three different upstream channel lengths of $1,1.5$ and $2.5 \mathrm{~m}$ are used to predict the effect of the channel length on simulation results. The results of these simulations are represented in Table 4.7. 
Table 4.7 Effect of upstream channel length on simulation results

\begin{tabular}{|c|c|c|c|c|c|c|}
\hline $\begin{array}{c}\text { Upstream } \\
\text { Channel } \\
\begin{array}{c}\text { Length } \\
(\mathrm{m})\end{array}\end{array}$ & $\begin{array}{c}h \\
(\mathrm{~m})\end{array}$ & $\begin{array}{c}h_{t}=h+P \\
(\mathrm{~m})\end{array}$ & $\begin{array}{c}Q_{\text {cal }} \\
\left(\mathrm{m}^{3} / \mathrm{s}\right)\end{array}$ & $\begin{array}{c}Q_{C F D} \\
\left(\mathrm{~m}^{3} / \mathrm{s}\right)\end{array}$ & $\begin{array}{c}R E \\
(\%)\end{array}$ & $\begin{array}{c}\text { Simulation } \\
\text { Time } \\
(\mathrm{hrs})\end{array}$ \\
\hline 2.5 & 0.15 & 0.25 & 0.01741 & 0.01740 & 0.057 & 32.11 \\
\hline 1.5 & 0.15 & 0.25 & 0.01741 & 0.01768 & -1.551 & 16.25 \\
\hline 1.0 & 0.15 & 0.25 & 0.01741 & 0.01770 & -1.666 & 10.34 \\
\hline
\end{tabular}

It is seen from Table 4.7 that the simulations with these upstream lengths give almost the same results by comparing $R E$ values. The other result seen from Table 4.7 is that the solution time increases with the longer upstream channel length. The channel length may be lengthened further but in this case the number of computational cells would increase significantly and hence would increase dramatically the simulation time. Since the numerical study includes different $h$ values and these $h$ values reach to relatively higher values than the experimental range, the upstream channel length of $2.5 \mathrm{~m}$ is accepted as sufficient to obtain accurate simulation results.

\subsubsection{Effect of Aeration}

The effect of aeration on the simulation results was also investigated for a particular case of Problem $2(a=0.16 \mathrm{~m}, y=0.09 \mathrm{~m}$, and $H=0.369 \mathrm{~m})$. Results showed that higher $R E$ value of $4.7 \%$ was obtained when compared to no aeration option of $4 \%$, therefore no aeration option was preferred in the simulations.

\subsubsection{Numerical Simulations Using Various Upstream Flow Depths}

Using the optimized model parameters of mesh size, turbulence model, and upstream channel length which were obtained from the studies given in the previous sections, systematical simulations have been performed for various upstream flow depths of the contracted weir given in Figure 2.1. The experimental values of upstream flow depth data for $b / B=0.5$ varied from $0.0256 \mathrm{~m}$ to $0.2730 \mathrm{~m}$. For this constant $b / B$ ratio, 
five flow depths within and three flow depths outside of the experimental range were given as initial boundary condition in the numerical model. The comparison of numerical and experimental results is given both in Table 4.8 and in Figure 4.1, while the variation of absolute values of $R E$ with the upstream flow depth $h_{t}$ is given in Figure 4.2. The results showed that the formulation given by Aydin et al. (2011) for discharge computation in contracted sharp crested weirs can be considered as valid both within and outside of the experimental range. Absolute values of the maximum and the minimum $R E$ were obtained as 6.197 and $0.053 \%$, respectively, indicating reasonably acceptable simulation results.

Table 4.8 Comparison of the experimental data with the numerical results

\begin{tabular}{|c|c|c|c|c|c|c|}
\hline $\begin{array}{c}h \\
(\mathrm{~m})\end{array}$ & $\begin{array}{c}h_{t}=h+P \\
(\mathrm{~m})\end{array}$ & $\begin{array}{c}Q_{\text {cal }} \\
\left(\mathrm{m}^{3} / \mathrm{s}\right)\end{array}$ & $\begin{array}{c}Q_{C F D} \\
\left(\mathrm{~m}^{3} / \mathrm{s}\right)\end{array}$ & $\begin{array}{c}\text { Computation } \\
\text { Time } \\
(\mathrm{sec})\end{array}$ & $\begin{array}{c}R E \\
(\%)\end{array}$ & $\begin{array}{c}\text { Simulation } \\
\text { Time } \\
(\mathrm{hrs})\end{array}$ \\
\hline 0.05 & 0.15 & 0.00336 & 0.00350 & 25 & -4.167 & 45.33 \\
\hline 0.10 & 0.20 & 0.00936 & 0.00994 & 25 & -6.197 & 16.76 \\
\hline 0.15 & 0.25 & 0.01741 & 0.01740 & 20 & 0.057 & 32.00 \\
\hline 0.20 & 0.30 & 0.02706 & 0.02700 & 20 & 0.222 & 18.79 \\
\hline 0.25 & 0.35 & 0.03796 & 0.03798 & 20 & -0.053 & 34.78 \\
\hline 0.30 & 0.40 & 0.04977 & 0.05022 & 25 & -0.904 & 54.44 \\
\hline 0.35 & 0.45 & 0.06220 & 0.06350 & 20 & -2.090 & 48.64 \\
\hline 0.45 & 0.55 & 0.08789 & 0.09220 & 20 & -4.904 & 65.94 \\
Within \\
exp. \\
range \\
outside \\
the exp. \\
range
\end{tabular}




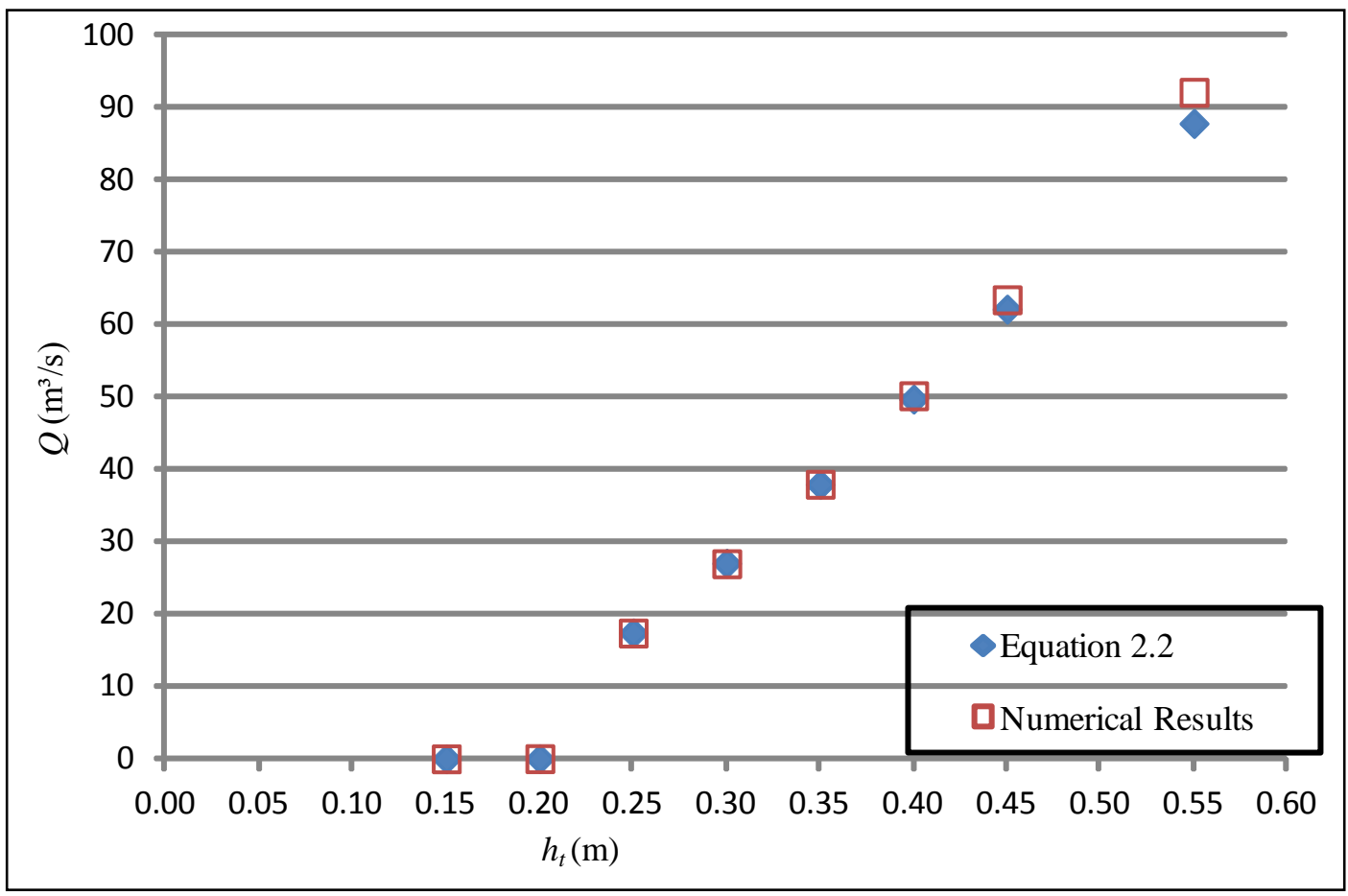

Figure 4.1 Comparison of the numerical simulations and experimental data

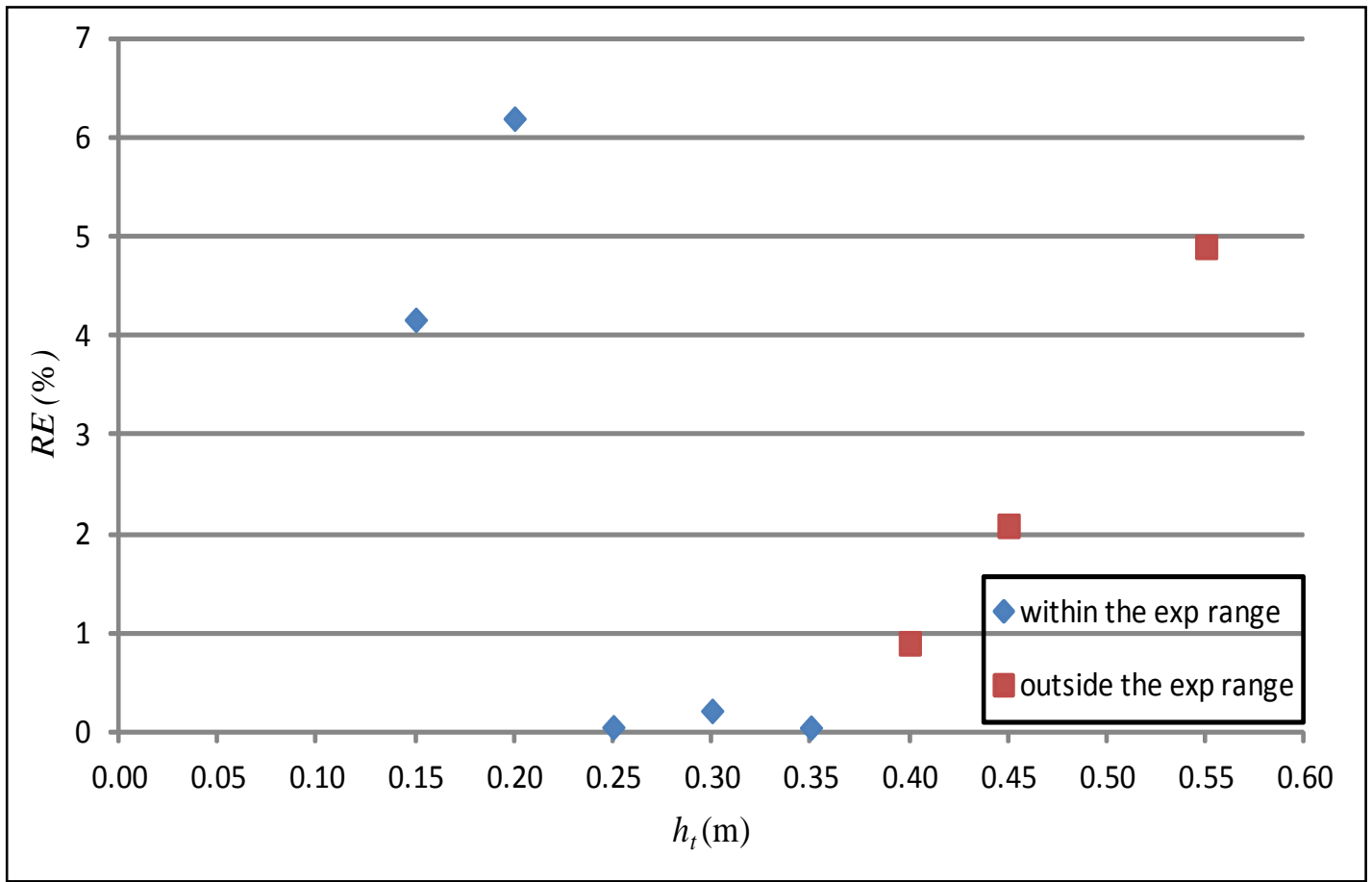

Figure 4.2 Variation of $R E$ with $h_{t}$ 


\subsection{PROBLEM 2}

The second problem was defined for the flow of water through a combined weir and gate system as previously sketched in Figure 2.3. Keeping the summation of " $a$ " and " $y$ " constant, (i.e. $a+y=0.25 \mathrm{~m})$, two different gate heights of " $a$ " (0.08 and 0.16 m) were considered in the second problem to investigate the effect of gate dimension on flow discharge through the combined system. Table 4.9 shows the simulation summary for the second problem. Totally, eight simulations were performed for the combined weir and gate system in which four of them with " $a=0.08 \mathrm{~m}$ " (Runs A1A4) and the other four of them with " $a=0.16 \mathrm{~m}$ " (Runs B1-B4). The " $b$ " value is equal to $0.2 \mathrm{~m}$ and constant for both geometries. A typical 3D-view of simulation result on velocity magnitude (RUN B2) for combined weir can be seen on Figure 4.3.

Decision on mesh cell size in the second problem is based on the information gained from the first problem. Although the mesh cell size was $4 \mathrm{~mm}$ in the first problem, it was chosen as $5 \mathrm{~mm}$ for the second problem. The cell size of $4 \mathrm{~mm}$ was also studied but simulations took a much longer computational time than $5 \mathrm{~mm}$. However, the $R E$ between these two different mesh cell sizes was negligible; therefore, $5 \mathrm{~mm}$ was preferred instead of $4 \mathrm{~mm}$ for the second problem. The turbulence model is also chosen the same as the first problem and it is RNG Turbulence Model.

In this part of the study, the experimentally determined discharge data by Askeroğlu (2006) and the numerically obtained discharge data by eight simulation runs were compared. The $R E$ values between these results were taken as reference for the comparison. At the same time, the combined system was divided into two parts in the CFD simulation with the help of the baffle option of Flow 3D. The discharge through the weir is obtained by making use of baffle and the discharge through the gate was obtained by using the baffle surface and subtracting the discharge over the weir from the total discharge. The results can be seen in Table 4.9, Table 4.10 and in Figure 4.4 indicating that CFD simulations predict the experimental data of flow discharge through combined weir system with a reasonable accuracy. The range of absolute value of $R E$ varies between $1.2-7.0 \%$ while the average value of $4.3 \%$ for all $R E$ 
values. In Table 4.9, it can be seen that, flow discharge was underestimated for the Combined Weir and Gate-A (except A1) and overestimated for the Combined Weir and Gate-B for all CFD simulations.

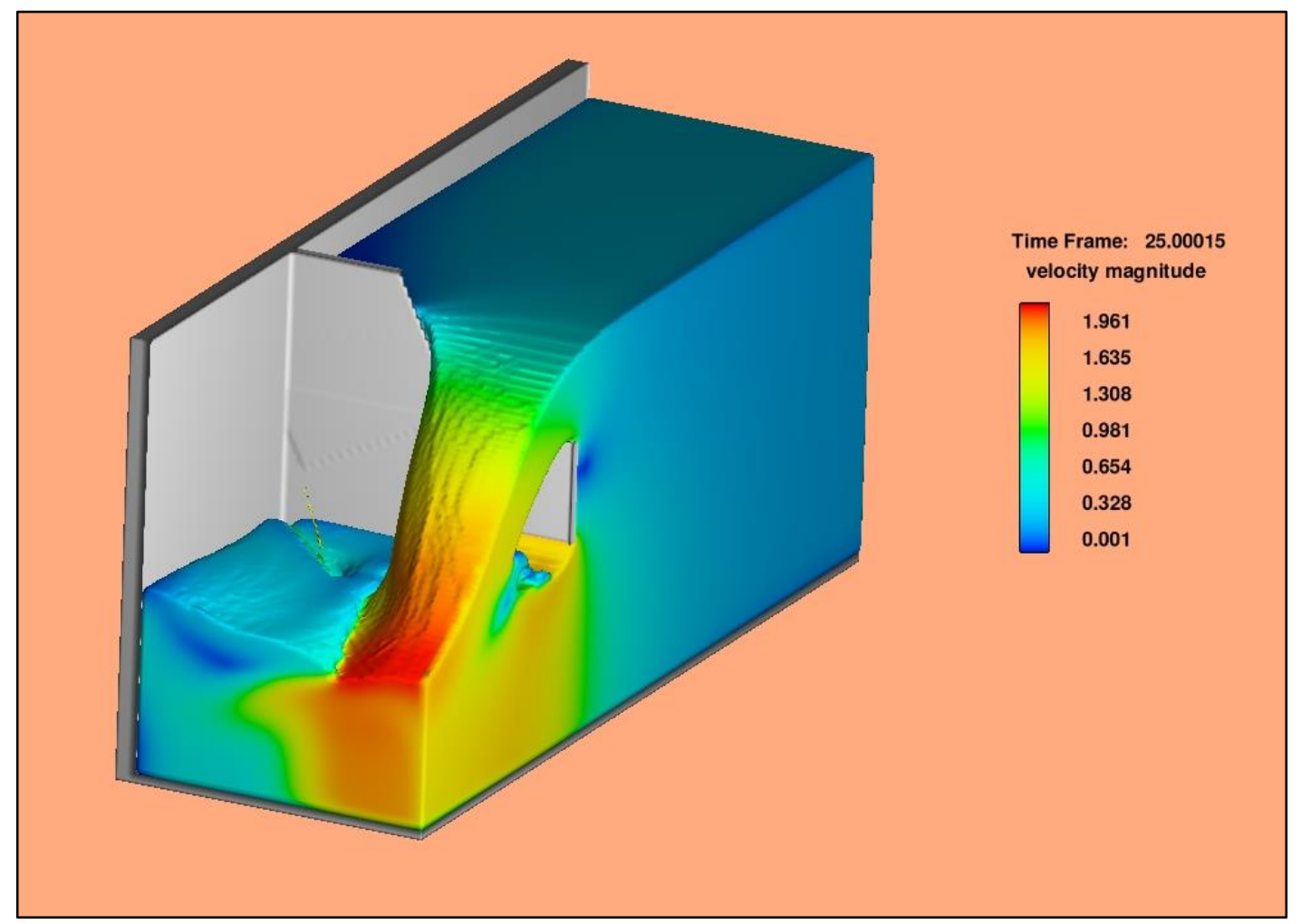

Figure. 4.3 Velocity magnitude from the simulation result for RUN B2 (in m/s) 
Table 4.9 Comparison of $Q_{c a l}$ and $Q_{C F D}$ results for the combined weir and gate systems

\begin{tabular}{|c|c|c|c|c|c|c|c|c|}
\hline $\begin{array}{c}\text { Run } \\
\text { no }\end{array}$ & $\begin{array}{c}a \\
(\mathrm{~m})\end{array}$ & $\begin{array}{c}y \\
(\mathrm{~m})\end{array}$ & $\begin{array}{c}b \\
(\mathrm{~m})\end{array}$ & $\begin{array}{c}h \\
(\mathrm{~m})\end{array}$ & $\begin{array}{c}H=h+y+a \\
(\mathrm{~m})\end{array}$ & $\begin{array}{c}Q_{\text {cal }} \\
(\mathrm{lt} / \mathrm{s})\end{array}$ & $\begin{array}{c}Q_{\text {CFD }} \\
(\mathrm{lt} / \mathrm{s})\end{array}$ & $\begin{array}{c}R E \\
(\%)\end{array}$ \\
\hline A1 & 0.08 & 0.17 & 0.2 & 0.0640 & 0.314 & 30.0 & 31.24 & 4.1 \\
\hline A2 & 0.08 & 0.17 & 0.2 & 0.1071 & 0.357 & 40.0 & 39.52 & -1.2 \\
\hline A3 & 0.08 & 0.17 & 0.2 & 0.1403 & 0.390 & 50.1 & 47.68 & -4.8 \\
\hline A4 & 0.08 & 0.17 & 0.2 & 0.1650 & 0.415 & 60.1 & 55.92 & -7.0 \\
\hline B1 & 0.16 & 0.09 & 0.2 & 0.0407 & 0.2907 & 40.0 & 42.74 & 6.9 \\
\hline B2 & 0.16 & 0.09 & 0.2 & 0.0859 & 0.336 & 50.1 & 52.60 & 5.0 \\
\hline B3 & 0.16 & 0.09 & 0.2 & 0.1194 & 0.369 & 60.1 & 62.50 & 4.0 \\
\hline B4 & 0.16 & 0.09 & 0.2 & 0.1451 & 0.395 & 69.9 & 71.16 & 1.8 \\
\hline
\end{tabular}




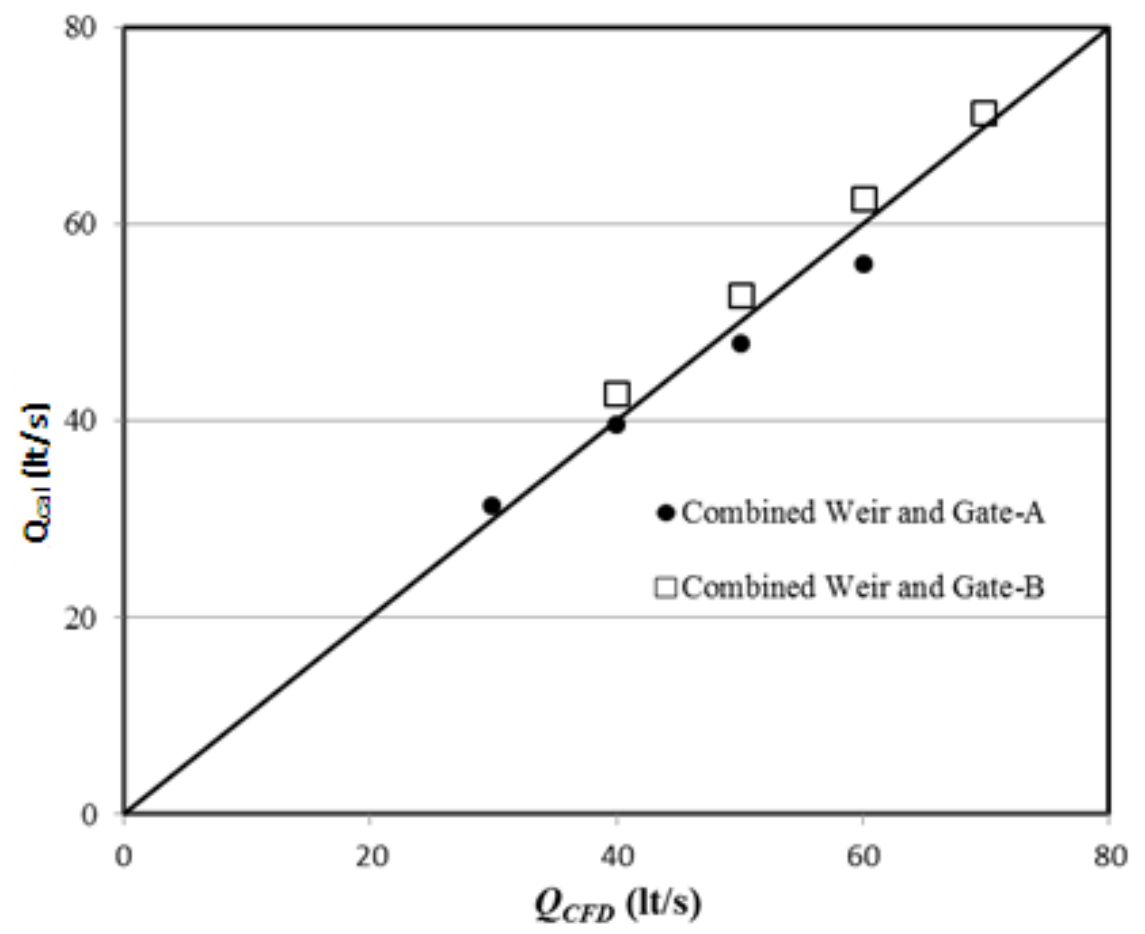

Figure 4.4 Comparison of $Q_{C F D}$ with $Q_{c a l}$ for Combined Weir and Gate Systems-A and-B

Figures 4.5-4.20 present 2D views of velocity magnitude contours and vectors at the centerline section of the combined weirs. At the upstream of the combined weir and gate systems, velocity magnitude contours and vectors show that a velocity field exists near the free surface and channel bottom regions although it is not the case for an individual weir or a gate. This is actually due to the combined effect of weir and gate arrangement causing acceleration of flow at the upstream approach channel. However, there is still a region, named as "dead zone", between the weir and gate (i.e. along the length " $y$ " given in Figure 2.3) having almost negligible velocity magnitude. Depending on the head over the weir, this dead zone slides upward or downward directions along the combined weir and gate component " $y$ ". In other words, if the head over the weir increases for a given gate height " $a$ " dead zone moves towards to the mid of the " $y$ " component (see Figures 4.11 and 4.19). Moreover, increase in head over the weir also increases submergence at the downstream flow due to predominant effect of the weir overflow on the flow through the gate. 


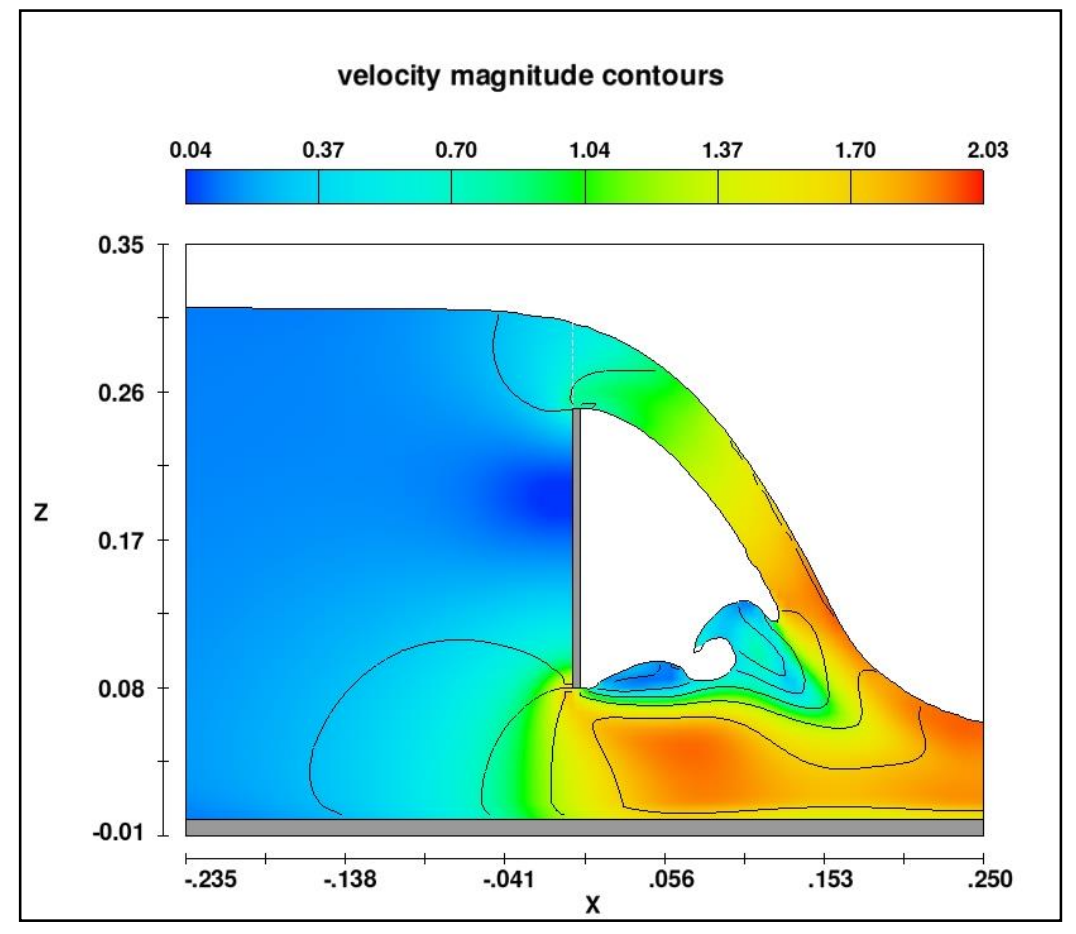

Figure 4.5 Velocity magnitude contours for RUN-A1 (in m/s)

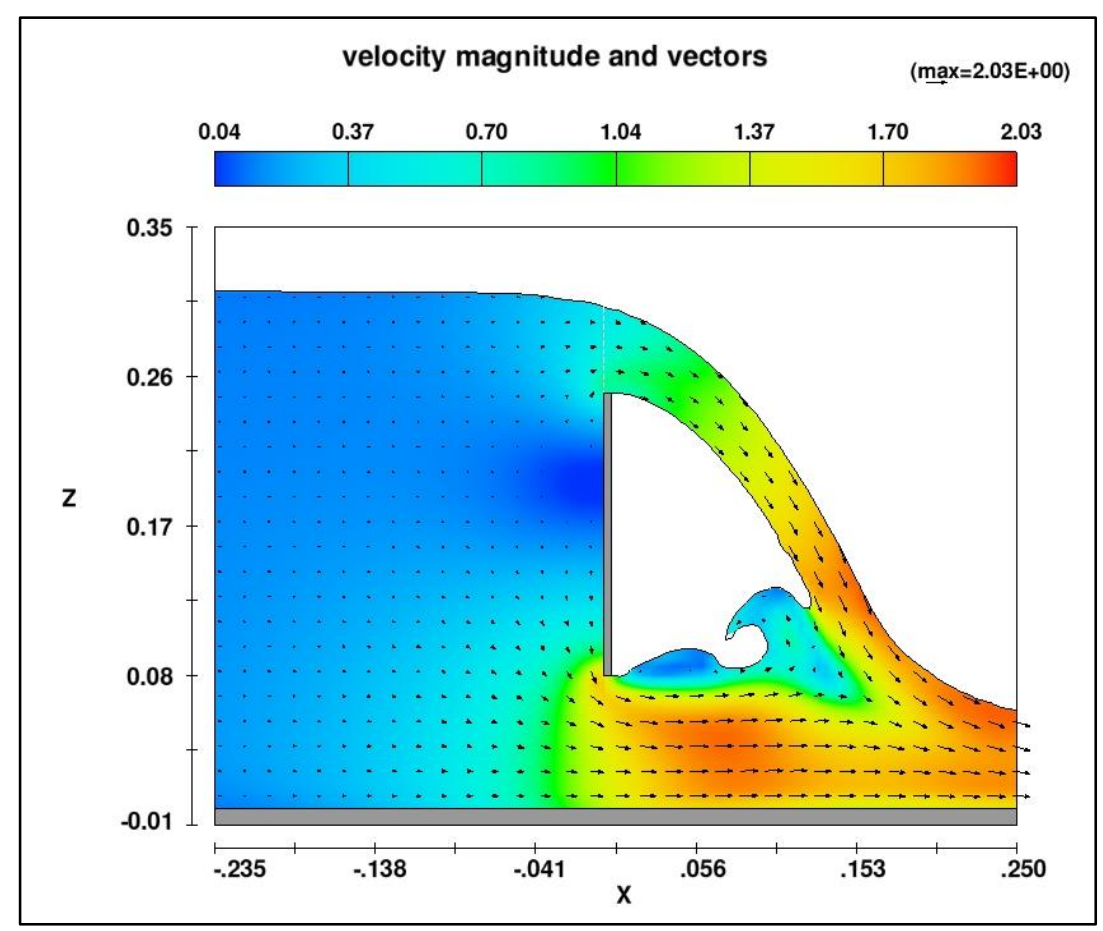

Figure 4.6 Velocity magnitude and vectors for RUN-A1(in m/s) 


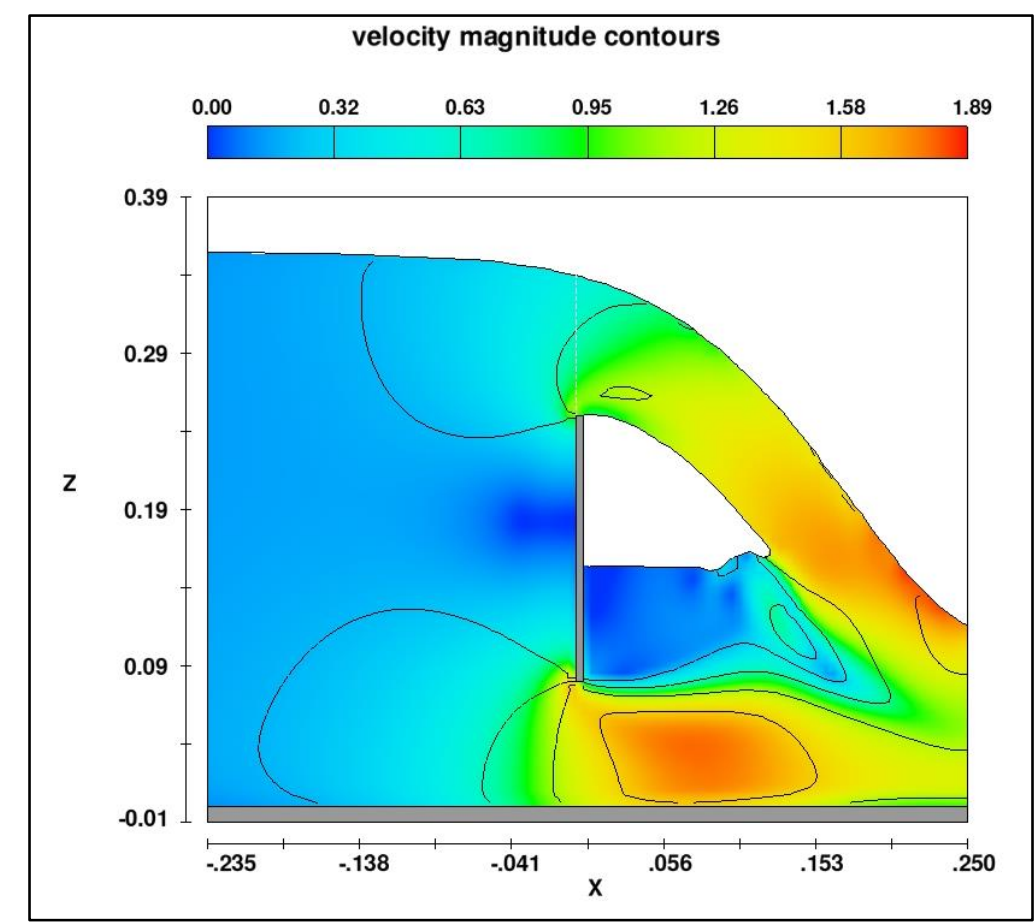

Figure 4.7 Velocity magnitude contours for RUN-A2 (in m/s)

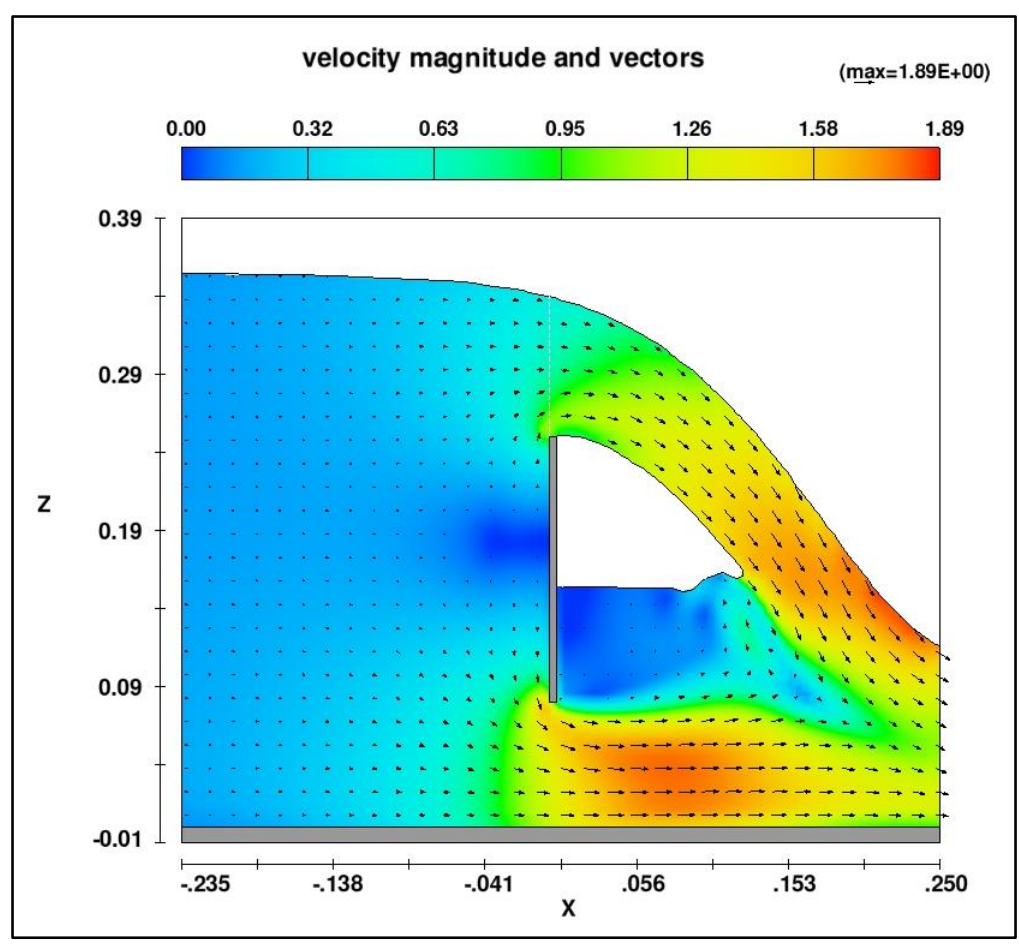

Figure 4.8 Velocity magnitude and vectors for RUN-A2 (in m/s) 


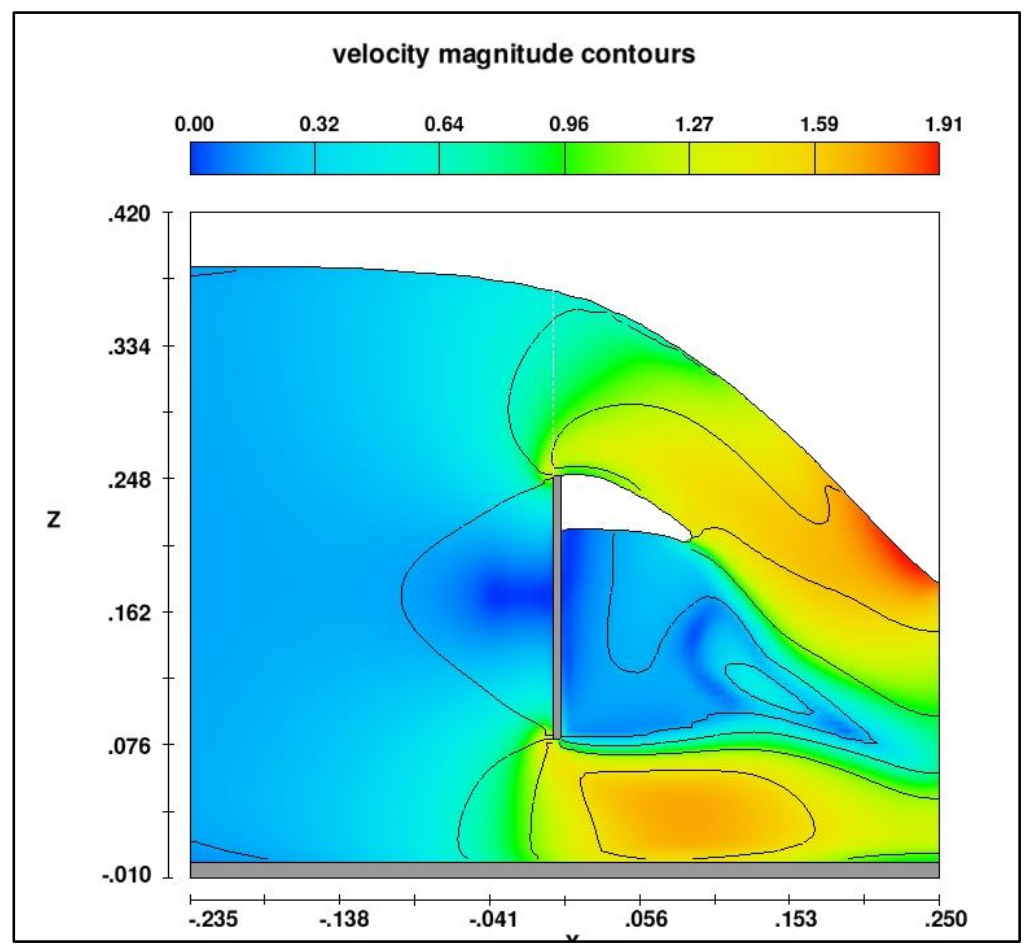

Figure 4.9 Velocity magnitude contours for RUN-A3 (in m/s)

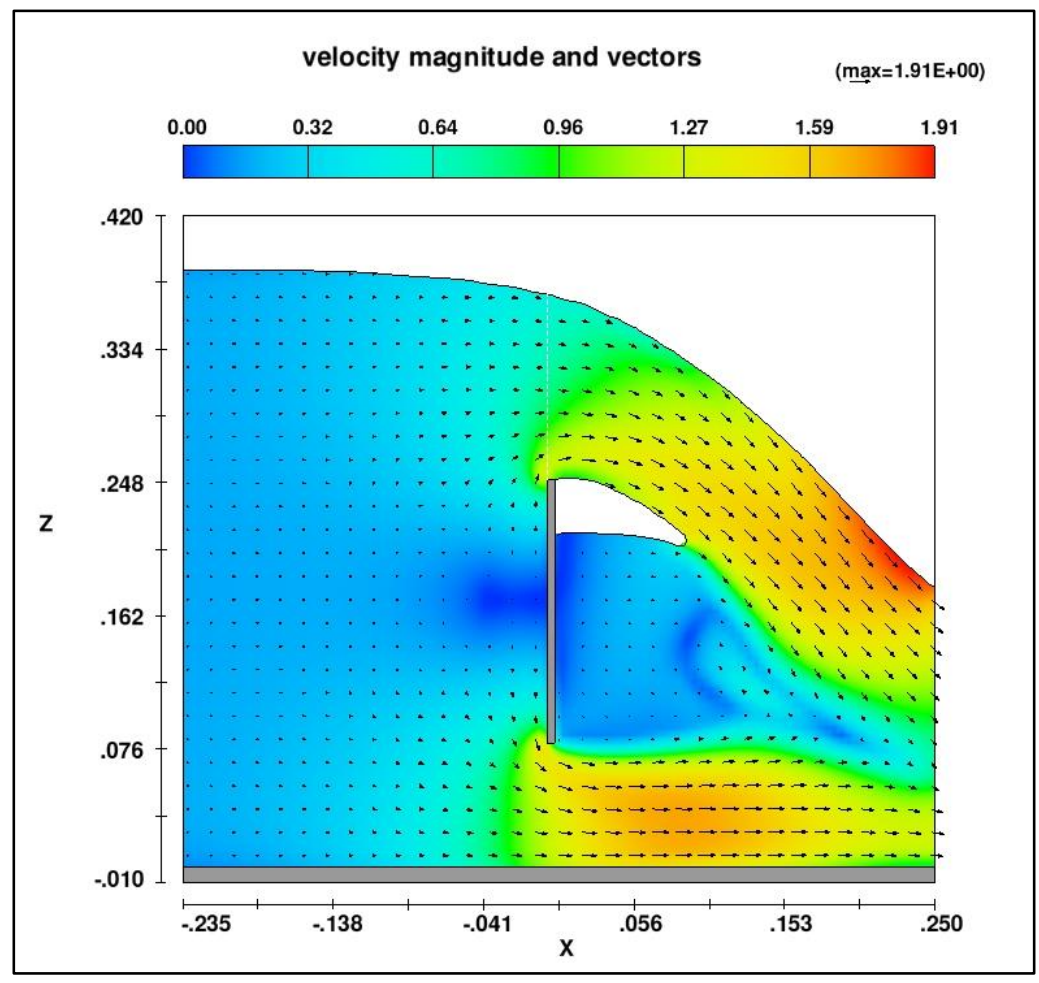

Figure 4.10 Velocity magnitude and vectors for RUN-A3 (in m/s) 


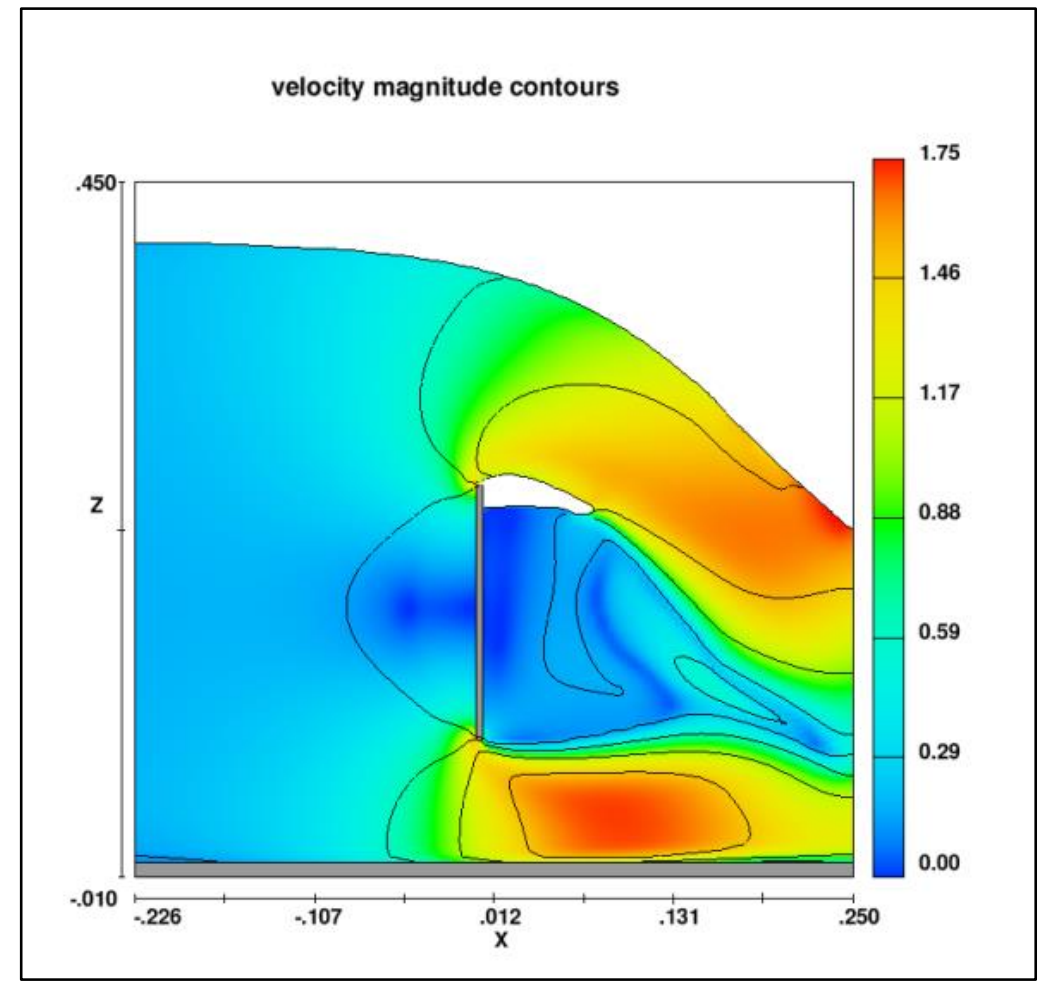

Figure 4.11 Velocity magnitude contours for RUN-A4 (in m/s)

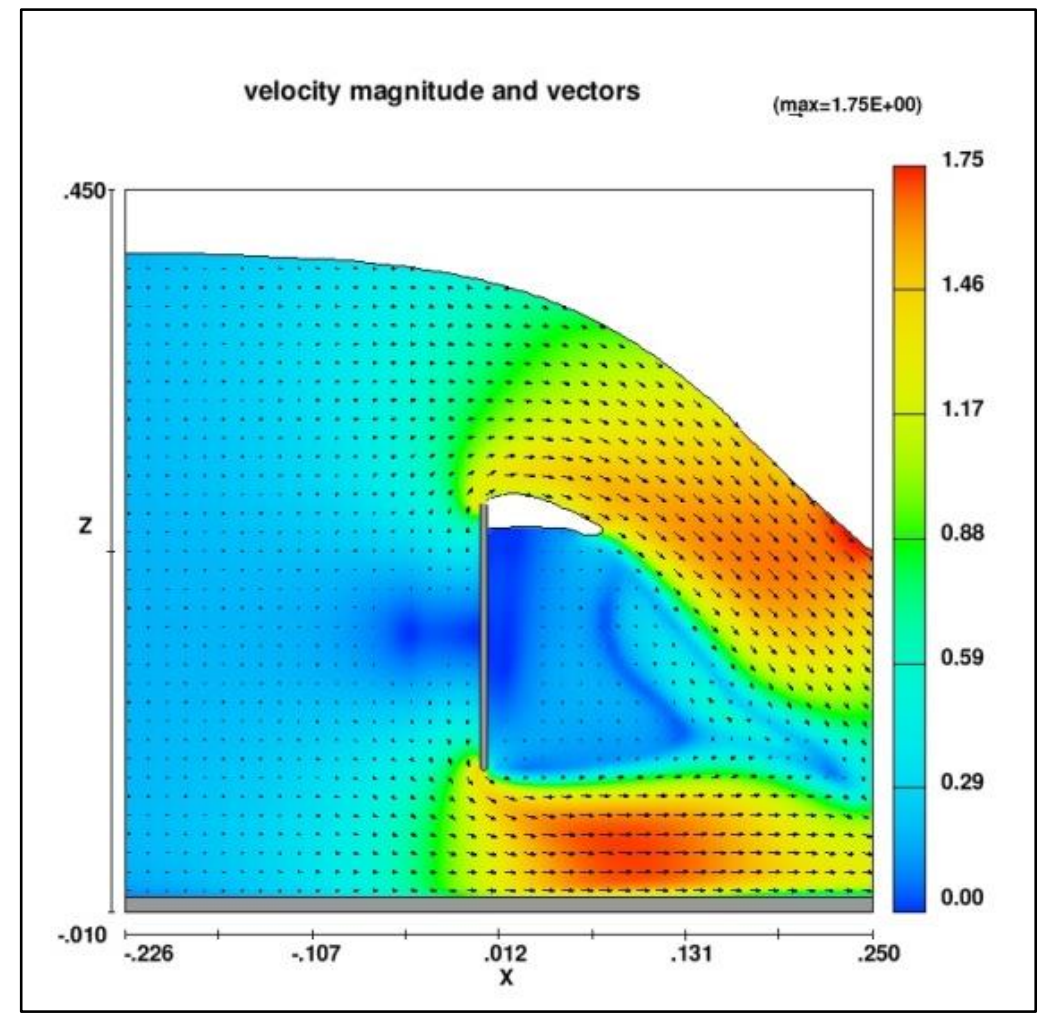

Figure 4.12 Velocity magnitude and vectors for RUN-A4 (in m/s) 


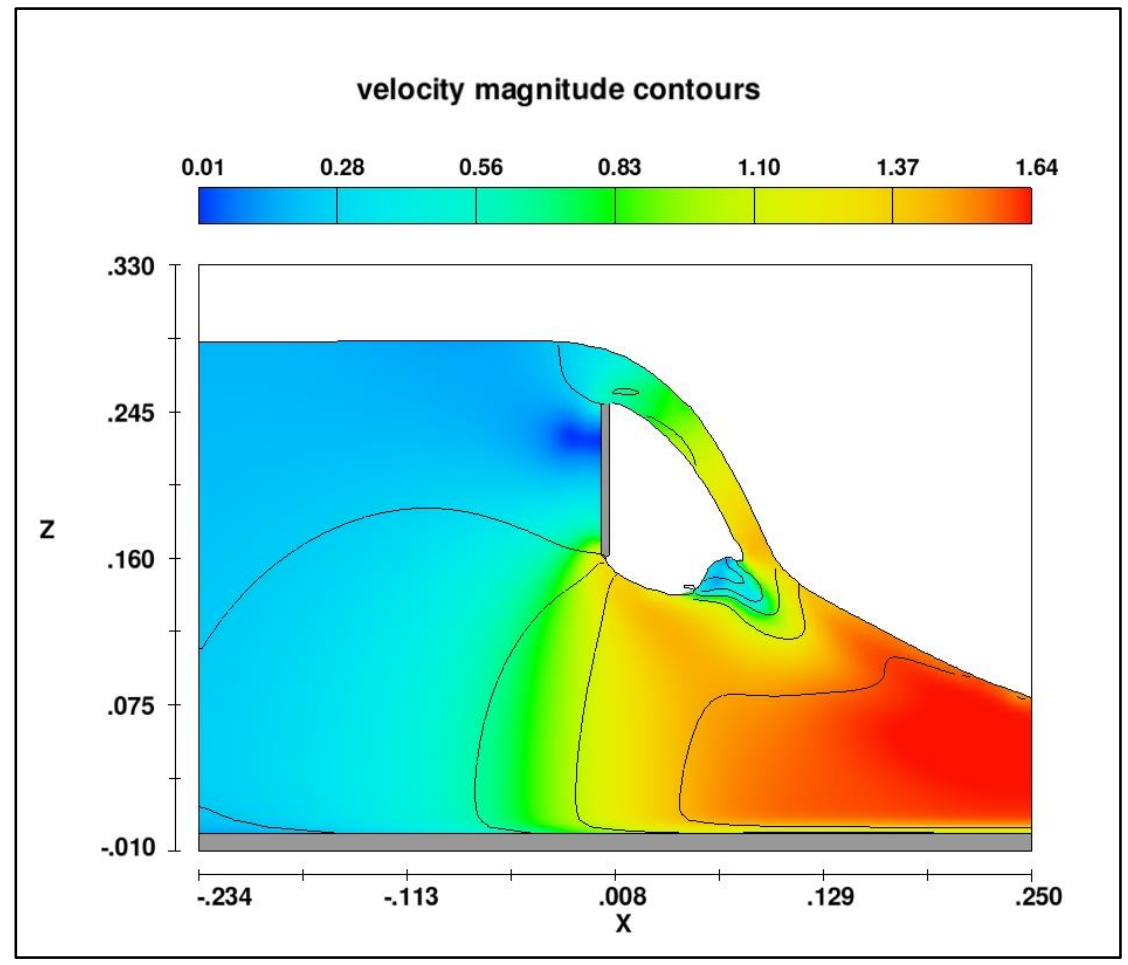

Figure 4.13 Velocity magnitude contours for RUN-B1 (in m/s)

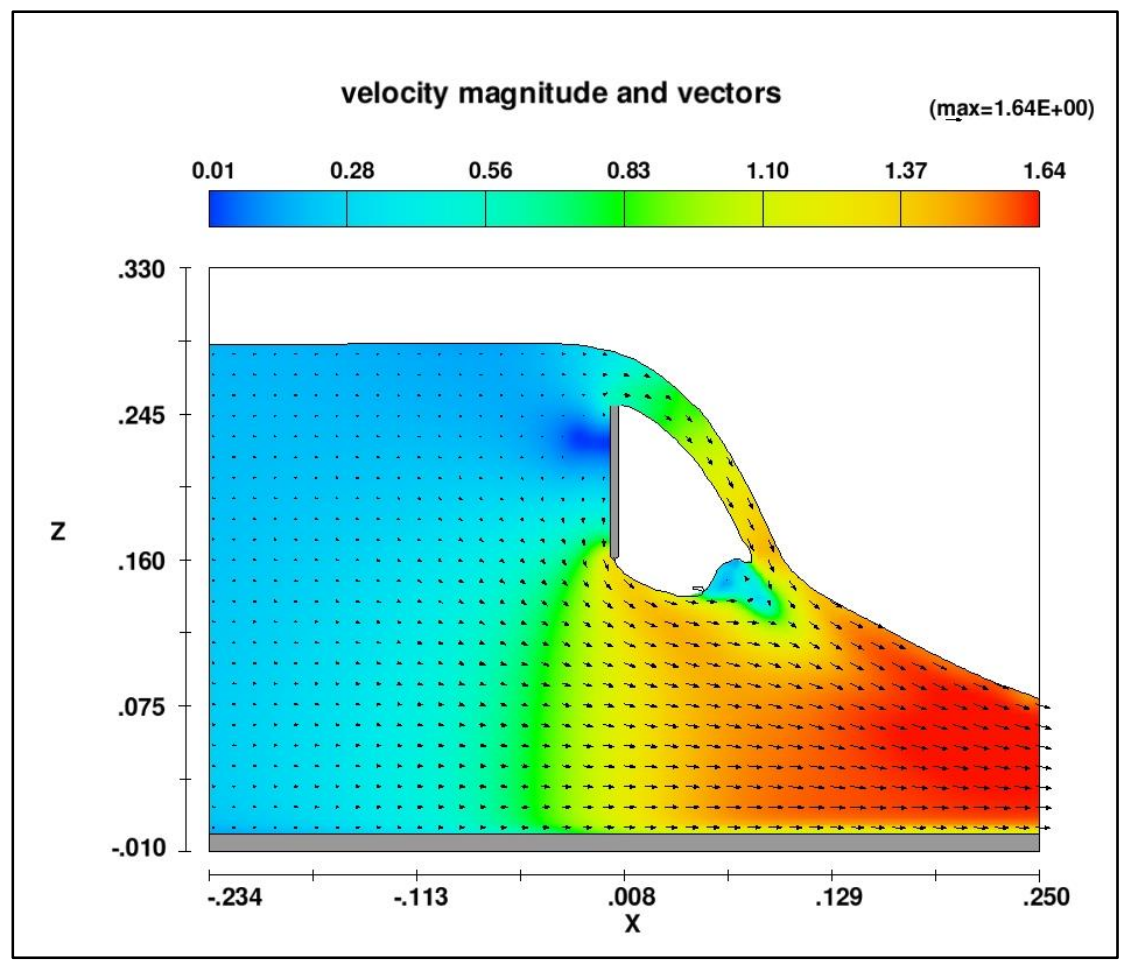

Figure 4.14 Velocity magnitude and vectors for RUN-B1 (in m/s) 


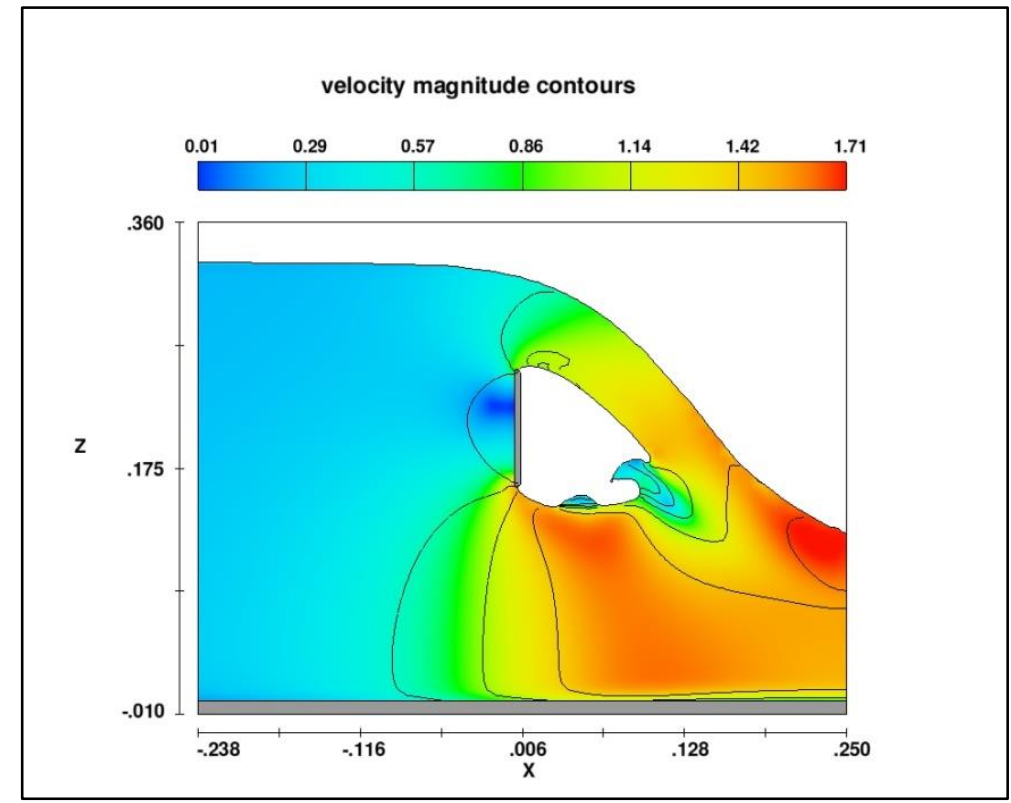

Figure 4.15 Velocity magnitude contours for RUN-B2 (in m/s)

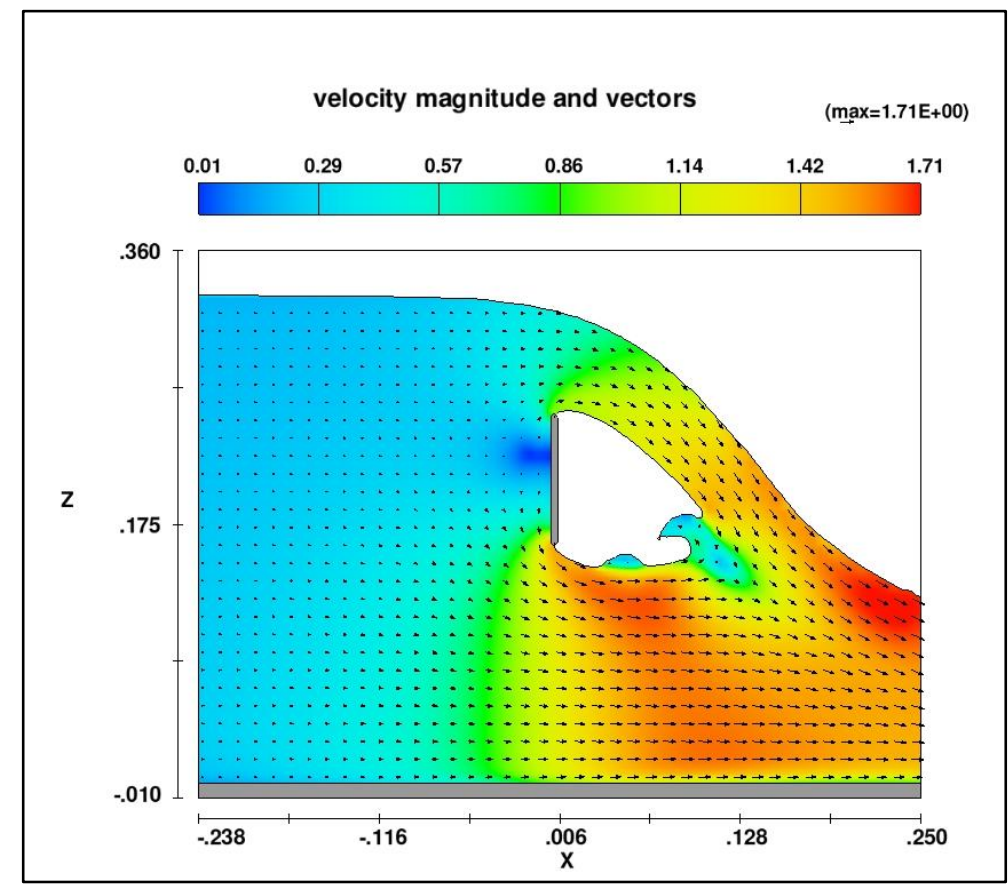

Figure 4.16 Velocity magnitude and vectors for RUN-B2 (in m/s) 


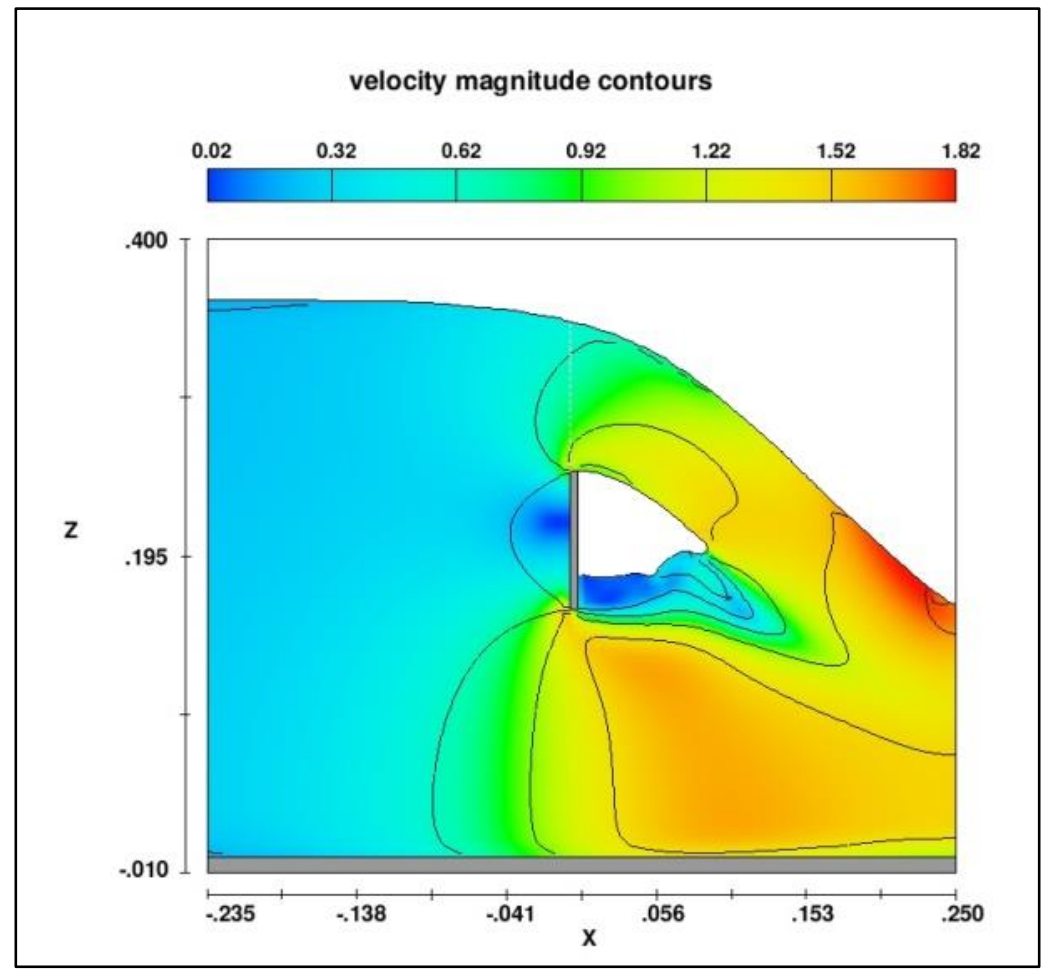

Figure 4.17 Velocity magnitude contours for RUN-B3 (in m/s)

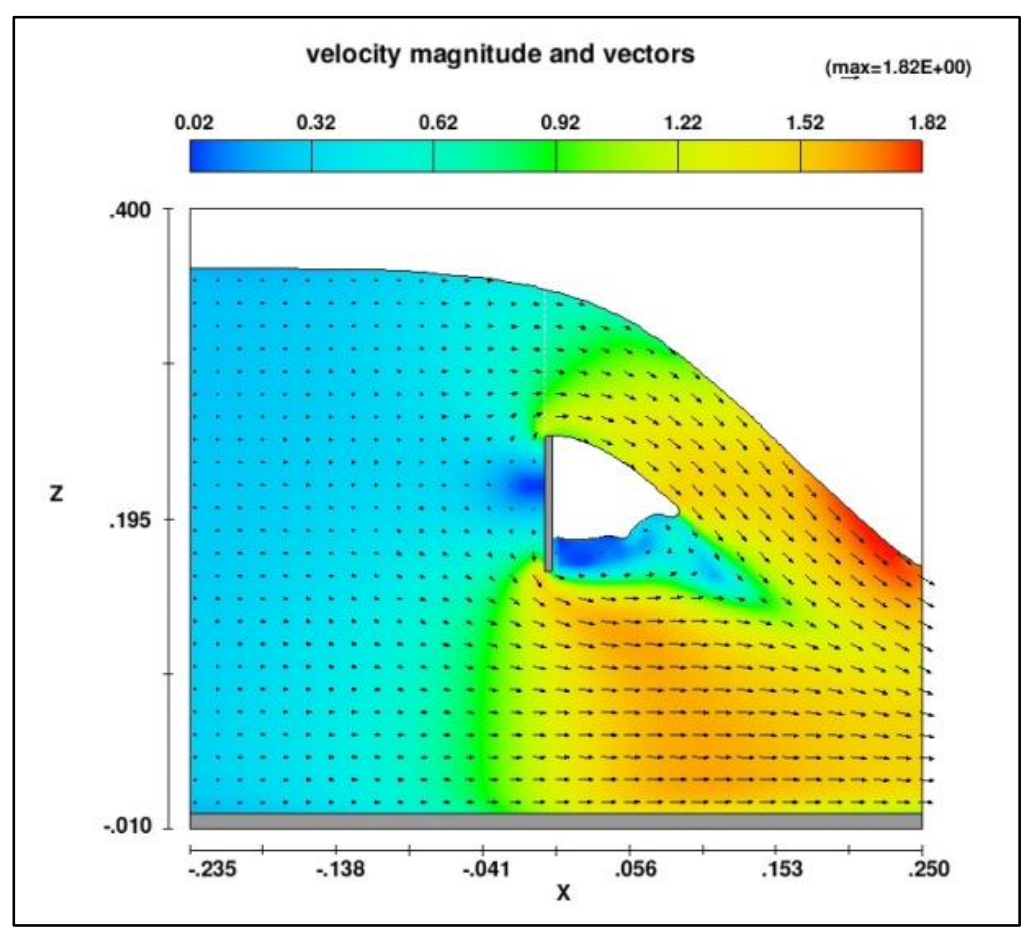

Figure 4.18 Velocity magnitude and vectors for RUN-B3 (in m/s) 


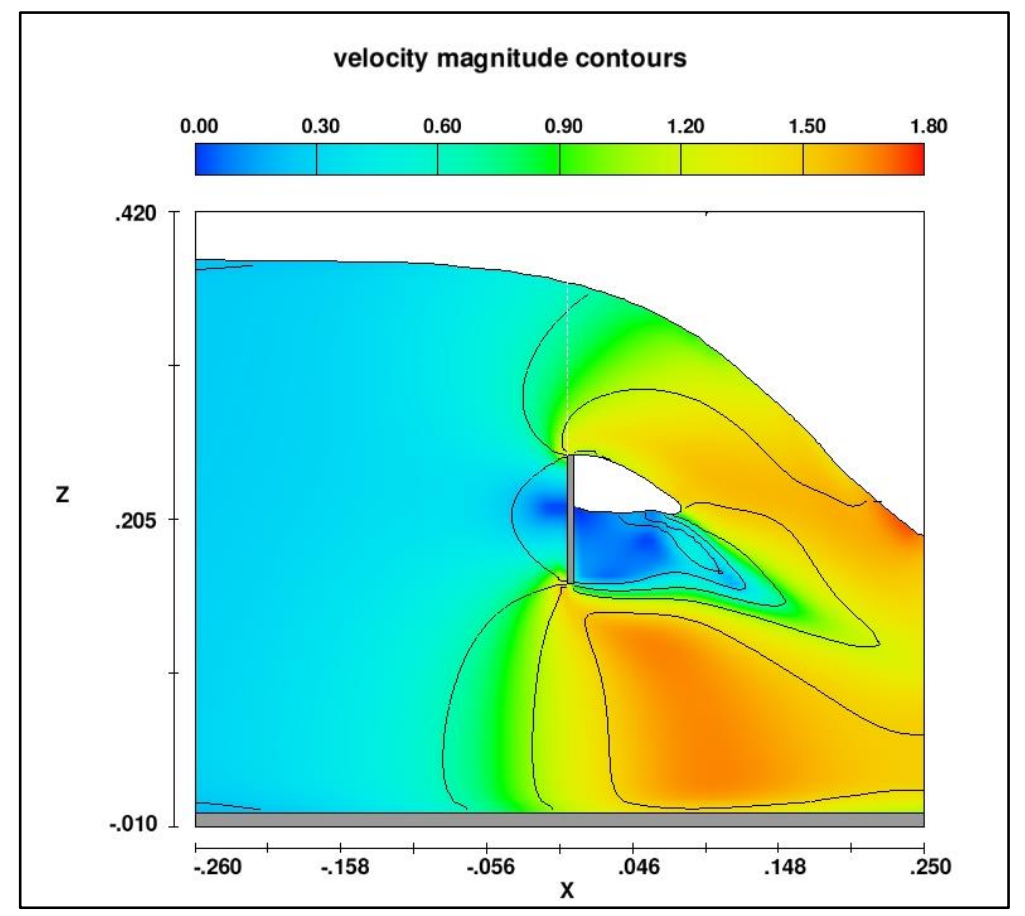

Figure 4.19 Velocity magnitude contours for RUN-B4 (in m/s)

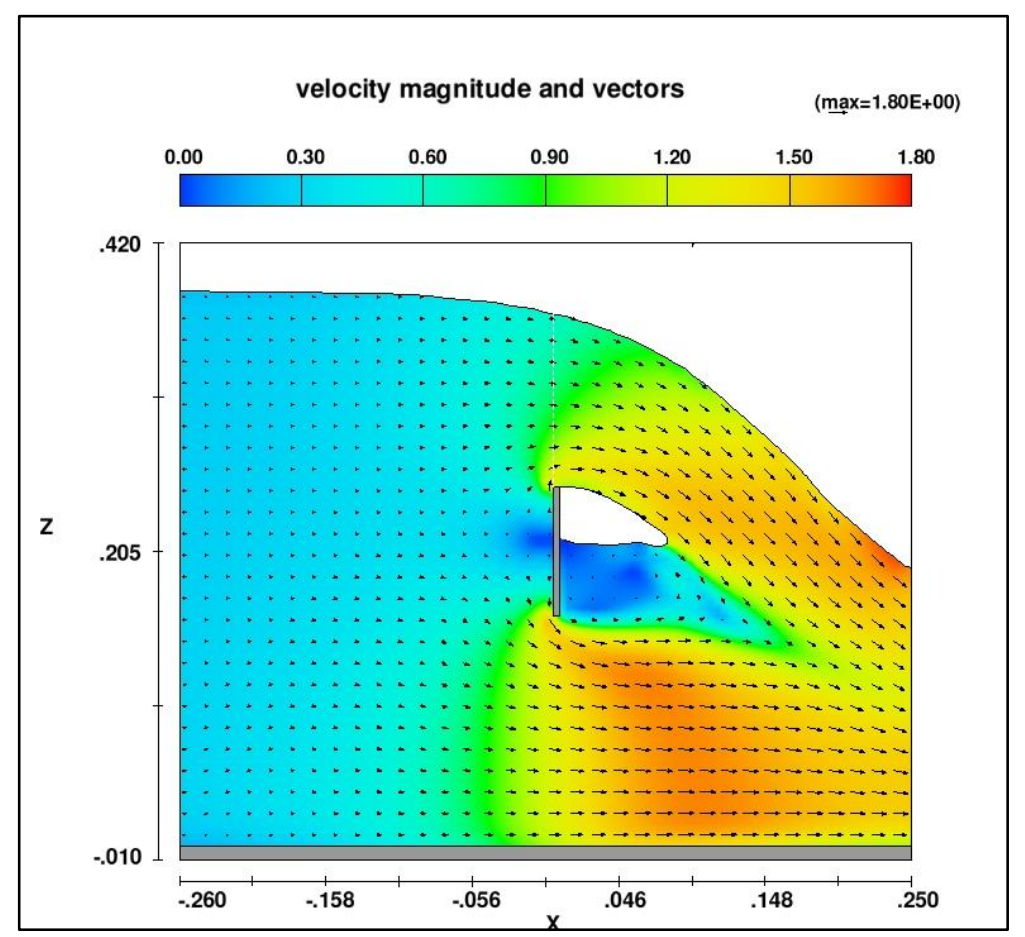

Figure 4.20 Velocity magnitude and vectors for RUN-B4 (in m/s) 
Discharge coefficients for the weir $C_{\text {weir }}$ and gate $C_{\text {gate }}$ can be computed separately with the use of baffle option in CFD modelling which are not possible to obtain experimentally. Table 4.10 shows discharge coefficients calculated from CFD modelling for the weir $\left(C_{\text {weir }}\right)_{C F D}$ and the gate $\left(C_{\text {gate }}\right)_{C F D}$.

In order to observe the trend of $\left(C_{\text {gate }}\right)_{C F D}$ with a non-dimensional upstream water head over the gate $(H / a)$, Table 4.10 and Figure 4.21 were constructed and plotted for the Combined Weir and Gate Systems-A and B, respectively. It can be clearly seen that as $H / a$ increases $\left(C_{\text {gate }}\right)_{C F D}$ decreases which is due to the impact effect of water jet issuing from the weir on the flow through the gate opening causing submergence of the gate flow. In other words, for low $H / a$ values (e.g. Runs A1 and B1) the effect of weir is limited on the gate discharge, however, increase in $H / a$ (e.g. Runs A4 and B4) results in significant decrease in gate discharge. The comparison between the CFD simulation results and experimental data for free flow through rectangular gates given by Bos (1989) was also shown in Figure 4.21. It is obviously seen that $\left(C_{\text {gate }}\right)_{C F D}$ values are always lower than the line of experimental data for both combined systems. For smaller gate openings having low head over the weir (e.g. case of RUN A1), $\left(C_{\text {gate }}\right)_{C F D}$ is very close to $\left(C_{\text {gate }}\right)_{\text {cal }}$ value because of the insignificant effect of weir flow on flow through the gate.

Askeroğlu (2006) conducted tests to determine discharge coefficient $\left(C_{\text {weir }}\right)_{\text {exp }}$ of the weir individually by closing the gate opening during the experiments. Almost a constant discharge coefficient value of $\left(C_{\text {weir }}\right)_{c a l}=0.60-0.61$ was obtained from these test results. However, results from CFD simulations showed a different tendency for the discharge coefficient of the weir when it operates together with a gate as shown in Figure 4.22. It can be seen that $\left(C_{w e i r}\right)_{C F D}$ values linearly decrease from 0.71 to 0.66 with increasing non-dimensional head over the weir $h /(y+a)$ for both combined weir and gate system geometries studied. In other words, discharge coefficient increases almost $18 \%$ for the cases of combined flow over weir and below gate systems. Since the approaching flow accelerated, the upstream velocity head is very important than a single weir case in which it is generally neglected. 
Table 4.10 Discharge and discharge coefficients computed from CFD modelling for the weir and gate

\begin{tabular}{|c|c|c|c|c|c|c|c|}
\hline $\begin{array}{c}\text { Run } \\
n o\end{array}$ & $\begin{array}{c}a \\
(\mathrm{~m})\end{array}$ & $\begin{array}{c}y \\
(\mathrm{~m})\end{array}$ & $\begin{array}{c}H=h+y+a \\
(\mathrm{~m})\end{array}$ & $\begin{array}{c}\left(Q_{\text {gate }}\right)_{\text {CFD }} \\
(\mathrm{lt} / \mathrm{s})\end{array}$ & $\begin{array}{c}\left(Q_{\text {weir }}\right)_{C F D} \\
(1 \mathrm{t} / \mathrm{s})\end{array}$ & $\left(C_{\text {gate }}\right)_{C F D}$ & $\left(C_{\text {weir }}\right)_{C F D}$ \\
\hline A1 & 0.08 & 0.17 & 0.314 & 23.70 & 7.54 & 0.597 & 0.700 \\
\hline A2 & 0.08 & 0.17 & 0.357 & 22.60 & 16.96 & 0.534 & 0.675 \\
\hline A3 & 0.08 & 0.17 & 0.390 & 21.60 & 26.00 & 0.488 & 0.655 \\
\hline A4 & 0.08 & 0.17 & 0.415 & 21.30 & 34.62 & 0.467 & 0.658 \\
\hline B1 & 0.16 & 0.09 & 0.2907 & 39.00 & 3.74 & 0.510 & 0.714 \\
\hline B2 & 0.16 & 0.09 & 0.336 & 40.76 & 11.84 & 0.496 & 0.680 \\
\hline B3 & 0.16 & 0.09 & 0.369 & 42.30 & 20.20 & 0.491 & 0.670 \\
\hline B4 & 0.16 & 0.09 & 0.395 & 42.98 & 28.18 & 0.482 & 0.670 \\
\hline
\end{tabular}

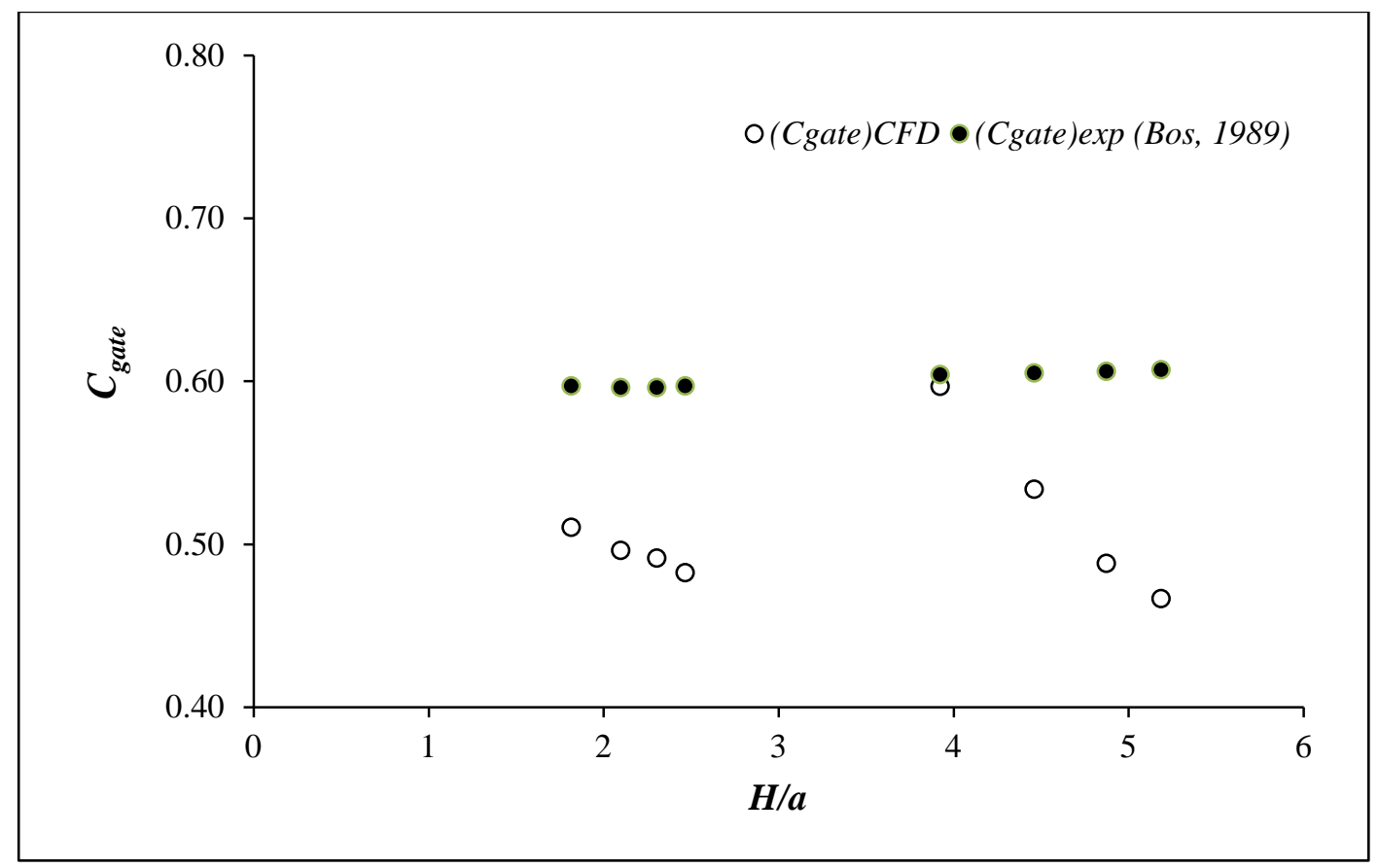

Figure 4.21 Correlation between $H / a$ and $C_{\text {gate }}$ 


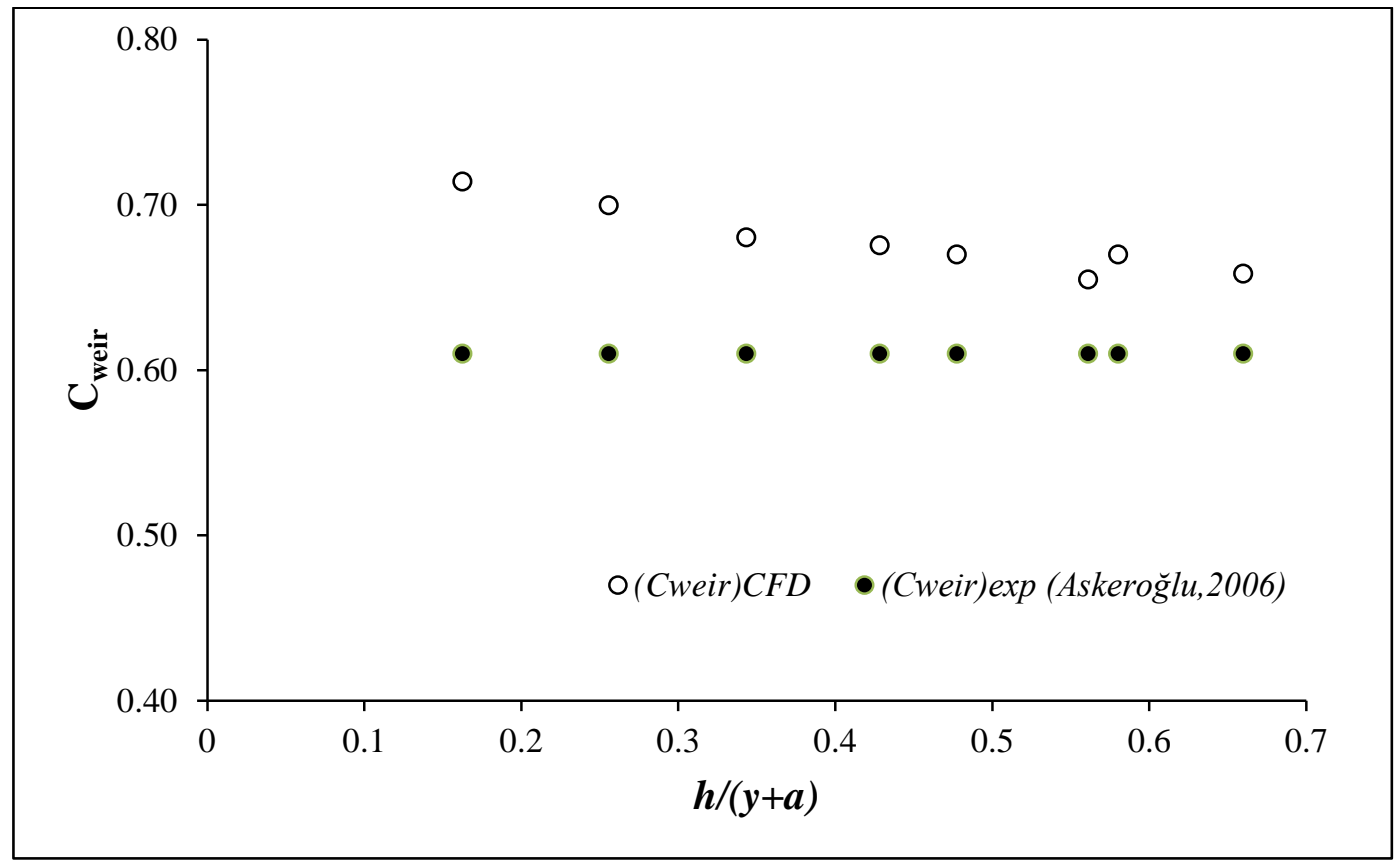

Figure 4.22 Correlation between $C_{\text {weir }}$ and $h /(y+a)$ ratio 


\section{CHAPTER 5}

\section{CONCLUSIONS}

A numerical simulation study was performed by using a commercially available CFD software Flow-3D in order to analyze flow characteristics for two discharge measurement structures; i.e. sharp crested contracted weir and combined weir and gate system which were named as Problem 1 and 2, respectively. Firstly, optimization of numerical model parameters such as mesh size, turbulence model type, upstream channel length, aeration effect were studied for two particular cases of Problems 1 and 2.

$\checkmark$ Optimization study proved the importance of selection of optimum mesh size in numerical simulations. Although minimizing the mesh size gives better results, it increases the computation time dramatically. It was deduced that mesh sizes of $4 \mathrm{~mm}$ and $5 \mathrm{~mm}$ were adequate to obtain sufficiently accurate simulation results for Problem 1 and 2, respectively.

$\checkmark$ RNG and LES turbulence models were tested to find the effect of turbulence model on the results of numerical simulations. RNG model was used in the simulations although both turbulence models gave similar results.

$\checkmark$ The upstream channel lengths of 1.0, 1.5 and $2.5 \mathrm{~m}$ were studied in the scope of the optimization study. Although similar results were obtained for all lengths, upstream channel length of $2.5 \mathrm{~m}$ was selected because lengthening the channel is considered hydraulically better for accuracy.

$\checkmark$ From the simulations, it was shown that flow aeration did not have an important effect on the simulations. Therefore, the aeration option was not chosen in the simulations. 
For Problem 1, it was seen that the relative error $(R E)$ between the formulation, obtained from regression analyses depending on the experimental data, given by Aydin et al. (2011) for contracted sharp crested weir and the CFD software results is relatively small.

$\checkmark$ For the Problem 2, dividing the combination of gate and weir system into two parts shows that the gate discharge and the weir discharge of the combined system are not equal to the individual system discharges. In other words, the total discharge of the combined system cannot be calculated by the summation of the individual weir and gate formulations. The discharge coefficients, $\left(C_{\text {gate }}\right)_{C F D}$ and $\left(C_{\text {weir }}\right)_{C F D}$ values are different from the experimental values. While $H / a$ increases, $\left(C_{\text {gate }}\right)_{C F D}$ decreases due to the impact effect of water jet issuing from the weir on the flow through the gate opening causing submergence of the gate flow. For the weir part, $\left(C_{\text {weir }}\right)_{C F D}$ values linearly decrease with increasing non-dimensional head over the weir $h /(y+a)$ values.

$\checkmark$ Normally, the velocity head is neglected for the individual weir analyses. However, when the weir system is combined with the gate, the upstream velocity head is very important, since the approaching flow is accelerated.

$\checkmark$ Eventually, it can be stated that CFD is a powerful tool in the solutions of hydraulic problems related to flow measurement structures. 


\section{REFERENCES}

Afshar, H., and Hoseini, H. S., (2013), "Experimental and 3-D Numerical Simulation of Flow over a Rectangular Broad- Crested Weir", International Journal of Engineering and Advanced Technology (IJEAT), ISSN: 2249 - 8958, Volume-2, Issue-6.

Alhamid A. A., (1999), "Analysis and formulation of fow through combined Vnotch-gate device", Journal of Hydraulic Research, 37(5):697-705.

Altan-Sakarya, A. B., and Kökpınar, M.A., (2013), "Computation of Discharge for Simultaneous over Weirs and Below Gates", Flow Measurement and Instrumentation, 29, p.32-38

Altan-Sakarya B., Ozaydin V., and Kokpinar M. A., (2005), "Birleşik çalışan savak ve kapaklarda debi ölçümü”, II.Ulusal Su Mühendisliği Sempozyumu, p.245-253 (In Turkish).

Askeroğlu, M. H., (2006), “Trapez savakların üzerinden ve kapakların altından olan kombine akımlar - Combined flows over trapezoidal weirs and below gates”. M.S. Thesis submitted to Gazi University.

Aydın, İ., Altan-Sakarya A. B, and Şisman, Ç., 2011, "Discharge Formula for Rectangular Sharp-Crested Weirs", Journal of Flow Measurement and Instrumentation 22, 144-151. 
Bagheri, S., and Heidarpour, M. (2010a), "Application of free vortex theory to estimating discharge coefficient for sharp crested weirs", Biosystems Engineering, 105: 423-7.

Bagheri, S., and Heidarpour, M. (2010b), "Flow over rectangular sharp crestedweirs", Irrigation Science, 28: 173-9.

Bos, M. G., (1989), “Discharge measurement structures”, Wageningen: International Institute for Land Reclamation and Improvement”, ILRI.

Ferro V. (2000), "Simultaneous flow over and under a gate", Journal of Irrigation and Drainage Engineering, ASCE, 126(3):190-3.

Flow Inc., Flow 3D User Manual v10.

Hargreaves, D. M., Morvan, H. P., and Wright, N. G (2007), "Validation of the Volume of Fluid Method for Free Surface Calculation: The Broad Crested Weir", Journal of Engineering Applications of Computational Fluid Mechanics Vol.1 No 2 pp 136-146.

Haun, S., Reidar, N., Olsen,B., and Feurich, R. (2011), "Numerical Modeling of Flow Over Trapezoidal Broad Crested Weir", Journal of Engineering Applications of Computational Fluid Mechanics Vol. 5 No 3 pp 397-405.

Henderson, F. M., (1967), “Open Channel Flow”, Macmillan Publishing Co. Inc. NY.

Hirt, C. W., and Nichols, B. D. (1981), "Volume of Fluid (VOF) method for the dynamics of free boundaries", Journal of Computational Physics, 39(1), pp. 201-225 
Kermani, E., and Barani, G. A., (2014), "Numerical simulation of flow over spillway based on the CFD method", Journal of Scientica Iranica Transactions A: Civil Engineering, 21(1) : 91-97.

Kindsvater C. E., and Carter, R. W., (1957), "Discharge characteristics of rectangular thin-plate weirs", Journal of Hydraulic Division ASCE, 1957(83), 1-36.

Negm A.M., Al-Brahim A.M., and Al Hamid A. A., (2002), "Combined free flow over weirs and below gates", Journal of Hydraulic Research, 40(3):359-65.

Ozmen-Cagatay, H., and Kocaman, S., (2010), "Dam-Break Flows During Initial Stage Using SWE and RANS Approaches", Journal of Hydraulic Research, 48 (5), 603-611.

Ramamurthy, A. S., Tim, U. S., and Rao, M. V., (1987), "Flow over sharp crested plate weirs", Journal of Irrigation and Drainage Engineering, ASCE, 113(2): 163-72.

Rehbock, T. (1929), "Discussion of precise weir measurements by EW Schoder and KB Turner. Trans", ASCE, 1143-62.

Şisman, Ç., (2009), "Experimental investigation on sharp crested rectangular weirs", M.S. Thesis submitted to Middle East Technical University.

Swamee, P. K., (1988), "Generalized rectangular weir equations", Journal of Hydraulic Engineering, 114(8):945-9.

http://www.flow3d.com/home/resources/cfd-101/free-surface-fluid-flow [last accessed on November,26,2014] 